\title{
Significance of the particle physical properties and the Geldart group in the use of correlations for the prediction of minimum fluidization velocity of biomass-sand binary mixtures
}

\author{
Louis Edwards Cáceres-Martínez ${ }^{1} \cdot$ Diana Carolina Guío-Pérez $^{1,2}$ (D) $\cdot$ Sonia Lucía Rincón-Prat ${ }^{1}$ \\ Received: 6 September 2020 / Revised: 22 November 2020 / Accepted: 1 December 2020 / Published online: 21 January 2021 \\ (C) The Author(s) 2021
}

\begin{abstract}
The present study explores the relevance of the physical properties of biomass particles on the determination of the minimum fluidization velocity $\left(U_{\mathrm{mf}}\right)$ of binary mixtures. Fluidization experiments were performed in a cold flow unit with diverse biomasses mixed with sand in different mass fractions. Gas velocity and pressure drop across the bed were used to determine $U_{\mathrm{mf}}$. Different correlations reported in the literature were evaluated on their ability to accurately predict $U_{\mathrm{mf}}$ of the mixtures. Results showed satisfactory predictions when appropriately identifying correlations according to the corresponding Geldart groups for the biomass particles. This perspective opens new possibilities toward the generalization of correlation factors and helps in improving the accuracy of the prediction for highly heterogeneous mixtures. The methodology also allows the analysis of mixtures for which the experimental approach is difficult, such as those including char particle, with the only requirement of carefully measuring the physical properties of the particles.
\end{abstract}

Keywords Gas-solid fluidization · Binary mixtures $\cdot$ Minimum fluidization velocity $\cdot$ Residual biomass $\cdot$ Pressure drop correlations $\cdot$ Geldart classification

\section{Introduction}

A continuous increase in the renewable power generation capacity has been observed in the last years. In 2018, nearly $11.4 \%$ of the total final energy demand was covered by bioenergy; however, from this percentage, traditional use of biomass accounted for $6.9 \%$ of the share [1]. This fact, along with the availability of residual biomass from agriculture, livestock, and forestry industries, has boosted the interest to research suitable transformation technologies that can add value to the productive economic chain and avoid inadequate use and disposal [2]. Energy use of residual biomass with low

Diana Carolina Guío-Pérez

dcguiop@unal.edu.co; carolina.guioperez@chalmers.se

1 Facultad de Ingeniería, Departamento de Ingeniería Mecánica y Mecatrónica, Grupo de Investigación en Biomasa y Optimización Térmica de Procesos-BIOT, Universidad Nacional de Colombia-Sede Bogotá, Carrera 30 No 45A-03 Edificio, 453 Bogotá, Colombia

2 Department of Space, Earth, and Environment, Chalmers University of Technology, Hörsalsvägen 7B, 41296 Göteborg, Sweden moisture content can satisfactorily be achieved through thermochemical processes (pyrolysis, combustion, gasification) and reach higher conversion efficiencies compared to physicochemical or biochemical process [3]. Despite the recent remarkable developments in the field, biomass thermochemical conversion still has challenges associated with characteristics of the feedstock, such as poor biological stability, extremely variable physical properties, ash melting issues, and comparative low heating values $[4,5]$.

Fluidized bed reactors for thermochemical conversion of biomass are a very convenient option, particularly for largescale applications. In comparison with the fixed and moving beds, fluidized beds have higher gas velocities and an increased turbulence, which improves the contact efficiency between the phases and, therefore, favors the progress of gassolid reactions [6]. The fluid-like behavior of the gas-solids suspension also allows the transport of solids to different sections of the system, which facilitates continuous processing [6]. In fact, conversion of solid fossil fuels, forest biomass, and municipal solid waste has been implemented in bubbling and circulating fluidized bed reactors, mainly for combustion. These units have proved technical flexibility and robustness, high thermal efficiencies, and low and controllable $\mathrm{NO}_{\mathrm{X}}$ 
emissions [7]. The good performance of this kind of systems strongly depends on the quality of the fluidization and the proper mixing of the fuel in the bed, which is not always easy to achieve when biomass is used as fuel.

The use of agro-industrial biomass residues in fluidized bed reactors entails a number of challenges, and some of them are related to the highly irregular physical properties of the particles. This is the case of the minimum fluidization velocity, which is usually predicted using correlations based on the theoretical relation between the total pressure drop in the bed and the non-dimensional numbers $A r$ and $R e$. The use of this method with highly heterogeneous binary mixtures is however still limited. In the present work, the fluid dynamic behavior of different types of biomass particles combined in binary systems with silica sand is studied together with the adequate measurement of the particle properties. As a result, the significance of the physical properties of the biomass particles and their Geldart classification on the selection of the suitable correlations for the determination of the minimum fluidization velocity has been revealed. The Geldart classification, first proposed in 1986 [8], seeks the categorization of particles according to their general behavior when fluidized. Although the classification is based on basic properties (density and size), it incorporates the extent of interparticle interactions in the bed and is the most widespread classification in the field of fluidized beds. This classification has already been considered for the study of biomass fluidization (not in a mixture) by several authors $[9,10]$ and has also been highlighted as an important aspect to be considered in binary beds [11].

The onset of fluidization and the transition to different fluidization regimes is well described for regular beds, that is, a bed made up of solids with high sphericity, homogeneous shapes throughout the whole range of sizes, and a normal monodisperse size distribution. Increasing the fluid velocity causes the particles to vibrate and move apart until the minimum fluidization velocity $U_{\mathrm{mf}}$ is reached. At this point, the particles are suspended by the upward-flowing fluid due to two main phenomena: (1) the frictional forces between the particles and the fluid counterbalance the weight of the bed, and (2) the vertical component of the compressive forces between adjacent particles becomes negligible [6]. Further increases in the flow rate beyond the minimum fluidization velocity introduce instabilities in the bed and result in the setting on of diverse fluidization regimes, depending on the properties of solids and gas, for example, smooth, bubbling, turbulent, fast, and pneumatic transport [7]. For homogeneous beds, theoretical equations that accurately predict the behavior of the bed have been developed. The most important equation is the one that relates pressure drop to the properties of gas and solids in a fixed bed, proposed by Ergun in 1952 [12]. This relation also allows the calculation of the minimum fluidization velocity for homogeneous beds.
Unlike coal, biomass particles are very irregular in size and shape ranging from grains to fibers, hulls, flakes or sticks, and are usually porous and pliable [13]. A bulk of particles often have no homogeneous sizes and shapes: size distribution in biomass is rather flat and bidisperse than monodisperse [14] and the shape varies throughout the size distribution. All these features make biomass samples difficult to fluidize; consequently, dealing with biomass as a fuel, especially in fluidized beds, requires a revision of the common analysis methods. For such irregular materials, the onset of the fluidization and the transitions between different fluidization regimes are significantly more difficult to predict. In fact, a considerable divergence from the regular behavior is always expectable. On this regard, besides the superficial gas velocity and the average physical properties of the gas and the particles, interactions between the particles and the variation of the physical properties within the bulk of solids should be considered [14-16].

Using a second, inert and regular material (silica sand or alumina, for instance) is a usual practice to facilitate the fluidization of highly heterogeneous particles such as biomass. The bed material helps to reduce the friction forces between particles during fluidization and regulates the heat transfer inside the bed [15]. Segregation may occur due to the differences in particles size and density between the materials [17], even though binary systems are extensively used in industrial applications, favoring fluid dynamic performance and conversion. In contrast to homogeneous beds, the minimum fluidization velocity of widely dispersed, that is, particle size distribution (PSD) different from normal, and heterogeneous (different physical properties, such as density or shape) systems are described by means of an initial fluidization velocity $U_{\text {if }}$ and a final fluidization velocity $U_{\mathrm{ff}}$, instead of a single minimum fluidization velocity [18]. Those velocities enable to define either a minimum fluidization velocity $U_{\mathrm{mf}}$ of the mixture or the partial or transient fluidization zone where the bed self-segregates [19].

Several researches have been conducting studies on the minimum fluidization velocities for biomass particles in binary systems [16, 20-28]. Most of them agree on the fact that there is no available, general correlation in the literature that accurately predicts experimentally measured $U_{\mathrm{mf}}$ for highly heterogeneous mixtures. In fact, relative errors higher than $20 \%$ are commonly reported between experimental and predicted minimum fluidization velocities $[24,29,30]$. In this sense, the present work aims to improve the methodology for the prediction of the minimum fluidization velocity of binary mixtures using biomass particles, by incorporating the Geldart classification, and to provide in this way key technical tools for the accurate design and operation of commercial fluidized bed reactors.

At this point, two remarks should be made regarding the physical properties of the biomass particles. On the one hand, the variability and heterogeneity of their physical properties 
(size, density, shape, and porosity) makes their measurement a very difficult task. Not only measurement methods should be carefully selected but also the uncertainty of the measurements should not be neglected, considering the relevance of these properties to the determination of fluid dynamic parameters [31]. In particular, size and shape are sensible parameters for which measurement methods should still be improved [32, 33]. On the other hand, biomass particles suffer a number of transformations when undergoing a thermochemical process and the changes in physical properties will also modify the fluid dynamical behavior of the bed [34]. The parameters of fluidization for mixtures containing biomass char could also be analyzed with the methodology presented here.

\section{Materials and methods}

\subsection{Biomass and bed material properties}

Oil palm shell, oil palm fiber, oil palm rachis, sugarcane bagasse, sugarcane top, rice husk, coffee husk, and poultry litter were selected based on their technical energy potential for use in thermochemical processes in Colombia [35]. The biomass samples were first dried to reach a moisture content below $15 \% \mathrm{w} / \mathrm{w}$, using a forced convection oven Binder FD-260. Afterward, the samples were grinded using a cutting mill Retsch SM-100 for shell and husk-type particles, and a hammer mill Agico CF420 for fiber-type particles. Fifteen different samples of biomass were generated as presented in Fig. 1: oil palm shell as received (Shell-AR) and ground (Shell-G), oil palm fiber coarsely (Fiber-CG) and finely (Fiber-FG) ground, oil palm rachis coarsely (Rachis-CG) and finely (Rachis-FG) ground, sugarcane bagasse coarsely (BagasseCG) and finely (Bagasse-FG) ground, sugarcane top coarsely (Top-CG) and finely (Top-FG) ground, rice husk as received (Rice H-AR) and ground (Rice $\mathrm{H}-\mathrm{G}$ ), coffee husk as received (Coffee H-AR) and ground (Coffee H-G), and poultry litter as received (Poultry L-AR).

The physical properties of the samples are summarized in Table 1. The particle size distribution was measured by sieving with a Ro-Tap Testing Sieve Shaker and a stack from U.S. Standardized Sieve Series. The mean particle size was calculated based on weight fractions [7]. The particle density was measured by pycnometry (UNE-EN-993-1) using liquid paraffin (density $830 \mathrm{~kg} / \mathrm{m}^{3}$ ). The sphericity was estimated by a stereo-microscope Nikon SMZ800 and 2D image analysis methodology [36]. Images of several particles of each sample were captured from three different planes. Perimeter and area were measured through ImageJ software and the mean sphericity of the particles was calculated using Sympatec's equation (Eq. 1) [32]. The moisture content was estimated following the standard procedure presented in the ASTM D4442 and the bulk density was measured as described in the ASTM
D2854-09. Finally, particles were classified in the Geldart diagram as shown in Fig. 2. Apart from particle size, all properties were measured three times. The dispersion range of the measurements is also presented in Table 1.

$\Phi_{\mathrm{p}-\text { sympatec }}=\frac{\sqrt{4 \pi S_{\mathrm{p}}}}{P_{\mathrm{e}}}$

The mean particle diameter of the bed material for a gasification process in a circulating fluidized bed is usually between 100 and $300 \mu \mathrm{m}$ [7]. In this work, silica sand with a mean particle size of $200 \mu \mathrm{m}$, bulk density of $1400 \mathrm{~kg} / \mathrm{m}^{3}$, particle density of $2600 \mathrm{~kg} / \mathrm{m}^{3}$, and mean sphericity of 0.81 was used as bed material. The Archimedes number calculated for this material is $A r=542.53$. With these properties, the sand can be classified as type B, according to Geldart (see Fig. 1). It should be pointed out that in general, the techniques available today for the determination of physical properties of fine bulk material have high inherent uncertainties [34]. This is a limitation yet to be overcome in handling of particulate materials.

\subsection{Preparation of binary mixtures}

Binary mixtures of $3 \%, 5 \%, 7 \%$, and $10 \%$ in mass (w/w) of biomass in sand were prepared. Those fractions were proposed in order to match the commonly reported concentrations in the literature (using sand as bed material) [20, 38], and to keep most mixtures suitable for fluidization. Depending on the characteristics of the biomass particles, mixtures with biomass concentrations beyond $20 \%$ in mass are likely to exhibit segregation and are therefore unsuitable for continuous operation [20, 22, 38]. Each binary mixture had a total mass of $2000 \mathrm{~g}$; this amount was selected in order to keep a bed aspect ratio $(H / D)$ at rest close enough to the unity and have a similar total pressure drop in the bed during fluidization. A constant aspect ratio at rest enhances the comparability of results since the wall effect should be similarly relevant for all experiments. Besides, the irregular flows observed in deep and shallow beds need to be avoided by approaching the aspect ratio to one. Given a constant mass for all the experiments, the total pressure drop should be constant as well, and the pressure profiles can be compared. For each experiment, the exact PSDs of both the original biomass sample and bed material were guaranteed. This means that for each of the 15 biomass samples, exactly the same PSD was replicated each time the sample was used, so that for a given sample, the four different mixtures contain exactly the same PSD of the biomass and the sand. A total of 52 mixtures were studied. For both oil palm fiber and oil palm rachis, mixtures of $7 \%$ and $10 \%$ in mass (w/w) (both coarsely and ground) could not be tested due to their low bulk densities and, consequently, excessive volume fraction in the mixture, which inhibited fluidization. 
Fig. 1 Pictures of the biomass samples after the conditioning processes: oil palm shell as received (Shell-AR), oil palm shell ground (Shell-G), oil palm fiber coarsely ground (Fiber-CG), oil palm fiber finely ground (Fiber-FG), oil palm rachis coarsely ground (Rachis-CG), oil palm rachis finely ground (Rachis-FG), sugarcane bagasse coarsely ground (Bagasse-CG), sugarcane bagasse finely ground (Bagasse-FG), sugarcane top coarsely ground (Top-CG), sugarcane top finely ground (Top$\mathrm{FG}$ ), rice husk as received (Rice $\mathrm{H}-\mathrm{AR}$ ), rice husk ground (Rice $\mathrm{H}$ $\mathrm{G})$, coffee husk as received (Coffee H-AR), coffee husk ground (Coffee $\mathrm{H}-\mathrm{G})$, and poultry litter as received (Poultry L-AR)

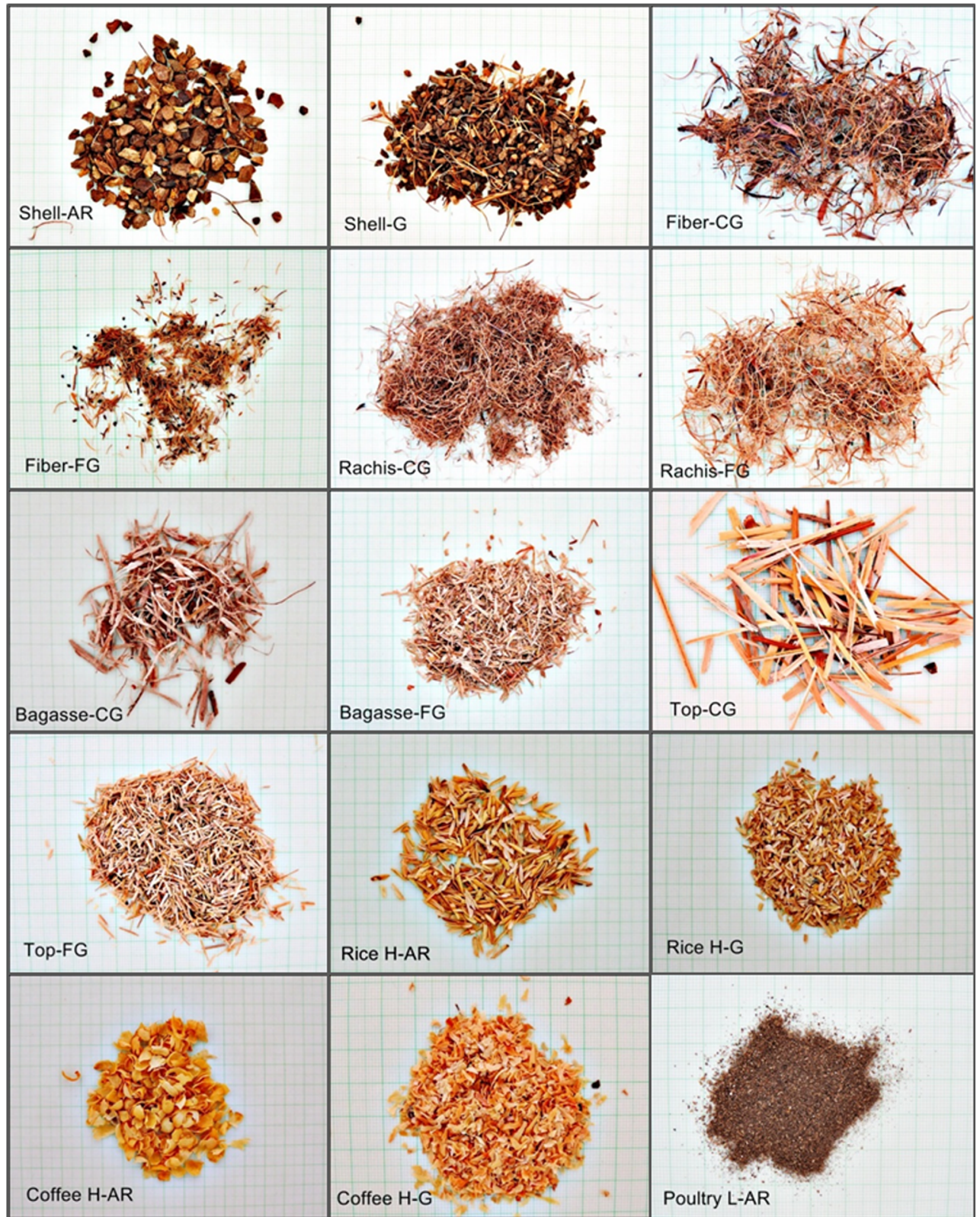

Experiments were performed twice for each system in order to confirm the repeatability of the main observations, that is, bed expansion and appearance of first bubbles or irregular fluidization (channels, segregation) are observed at similar gas velocities. If repeatable, the first measurement was analyzed in detail, if not repeatable, the mixture was removed from the analysis.

\subsection{Experimental facility and procedure}

The experimental facility depicted in Fig. 3 was used to test the fluid dynamic behavior of the mixtures. The unit is composed of a cylindrical fluidization chamber made of acrylic glass with an internal diameter of $13.5 \mathrm{~cm}$ and a height of
$67.0 \mathrm{~cm}$, a cyclone to separate elutriated particles, and a fabric filter for the fine particles. Pressure was measured using differential sensors with 0.1 mbar resolution, located at eight points: one before the distributor plate and seven along the chamber wall (1 to 7), as indicated in Fig. 3. Compressed air at room temperature was used as fluidization medium. At ambient conditions in Bogotá $\left(p_{\mathrm{o}}=74.66 \mathrm{kPa}\right.$ and $T_{\mathrm{o}}=18^{\circ}$ C), air density and viscosity are $0.8878 \mathrm{~kg} / \mathrm{m}^{3}$ and $1.83 \times$ $10^{-5} \mathrm{~Pa} \mathrm{~s}$, respectively. The gas flow rate was regulated using a rotameter with needle valve Cole-Parmer GZ-32461-60 with a scale of 10-100 1/min at standard conditions. The distributor is a flat perforated plate with a free fraction area of $23 \%$ and circular holes of $1 \mathrm{~mm}$ in diameter, arranged in a triangular pattern. Ground strips of copper and a graduated scale were 
Table 1 Physical characteristics of the biomass samples analyzed

\begin{tabular}{|c|c|c|c|c|c|c|c|}
\hline Sample & $\begin{array}{l}\text { Moisture } \\
\text { content } \\
\%\end{array}$ & $\begin{array}{l}\text { Mean particle } \\
\text { size } \\
\mu \mathrm{m}\end{array}$ & $\begin{array}{l}\text { Particle size distribution width P10- } \\
\text { P90 } \\
\mu \mathrm{m}\end{array}$ & $\begin{array}{l}\text { Bulk } \\
\text { density } \\
\mathrm{kg} / \mathrm{m}^{3}\end{array}$ & $\begin{array}{l}\text { Particle } \\
\text { density } \\
\mathrm{kg} / \mathrm{m}^{3}\end{array}$ & $\begin{array}{l}\text { Sphericity } \\
-\end{array}$ & $\begin{array}{l}\text { Geldart's particle } \\
\text { type }\end{array}$ \\
\hline Shell-AR & $8.8 \pm 0.7$ & 2576 & $1330-7830$ & $595 \pm 31$ & $1375 \pm 128$ & $0.69 \pm 0.15$ & D \\
\hline Shell-G & $10.6 \pm 0.2$ & 1781 & $1120-3330$ & $707 \pm 5$ & $1276 \pm 11$ & $0.71 \pm 0.13$ & $\mathrm{D}$ \\
\hline Fiber-CG & $10.5 \pm 0.2$ & 340 & $158-3960$ & $43 \pm 8$ & $1350 \pm 47$ & $0.24 \pm 0.05$ & $\mathrm{~B}$ \\
\hline Fiber-FG & $13.7 \pm 0.4$ & 201 & $87-1090$ & $200 \pm 3$ & $1317 \pm 45$ & $0.46 \pm 0.17$ & $\mathrm{AB}$ \\
\hline Rachis-CG & $9.7 \pm 0.1$ & 709 & $240-8660$ & $35 \pm 18$ & $1073 \pm 18$ & $0.27 \pm 0.08$ & B \\
\hline Rachis-FG & $10.1 \pm 0.2$ & 352 & $171-1980$ & $98 \pm 25$ & $1382 \pm 15$ & $0.30 \pm 0.17$ & $\mathrm{~B}$ \\
\hline Bagasse-CG & $10.2 \pm 0.2$ & 888 & $460-3260$ & $75 \pm 25$ & $579 \pm 154$ & $0.47 \pm 0.22$ & B \\
\hline Bagasse-FG & $9.9 \pm 0.3$ & 545 & $308-1940$ & $153 \pm 7$ & $814 \pm 33$ & $0.55 \pm 0.26$ & B \\
\hline Top-CG & $8.1 \pm 0.1$ & 912 & $462-4190$ & $109 \pm 17$ & $662 \pm 33$ & $0.47 \pm 0.17$ & B \\
\hline Top-FG & $7.5 \pm 0.3$ & 623 & $353-1930$ & $171 \pm 15$ & $993 \pm 166$ & $0.52 \pm 0.17$ & B \\
\hline Rice H-AR & $11.5 \pm 0.2$ & 1040 & $790-2330$ & $154 \pm 8$ & $1093 \pm 4$ & $0.36 \pm 0.22$ & $\mathrm{BD}$ \\
\hline Rice H-G & $10.8 \pm 0.3$ & 395 & $215-1820$ & $292 \pm 4$ & $1277 \pm 76$ & $0.42 \pm 0.19$ & B \\
\hline $\begin{array}{l}\text { Coffee } \\
\text { H-AR }\end{array}$ & $6.3 \pm 0.3$ & 1580 & $930-4150$ & $207 \pm 15$ & $1283 \pm 43$ & $0.42 \pm 0.17$ & $\mathrm{D}$ \\
\hline Coffee H-G & $9.5 \pm 0.2$ & 1032 & $689-2860$ & $305 \pm 5$ & $1306 \pm 88$ & $0.47 \pm 0.11$ & $\mathrm{BD}$ \\
\hline $\begin{array}{l}\text { Poultry } \\
\text { L-AR }\end{array}$ & $14.9 \pm 0.4$ & 258 & $117-2970$ & $544 \pm 7$ & $1403 \pm 74$ & $0.88 \pm 0.05$ & $\mathrm{~B}$ \\
\hline
\end{tabular}

The deviation of the measurements shown is calculated based on three equivalent experiments

attached to the walls of the chamber to prevent electrostatic charging and measure the bed expansion during experimentation, respectively.

An initial pre-fluidization was carried out at the beginning of each experiment by sharply increasing the fluidization velocity and then cutting off the gas flow. In this way, the possible preferential packaging of the bed was avoided. Subsequently, the superficial gas velocity was gradually

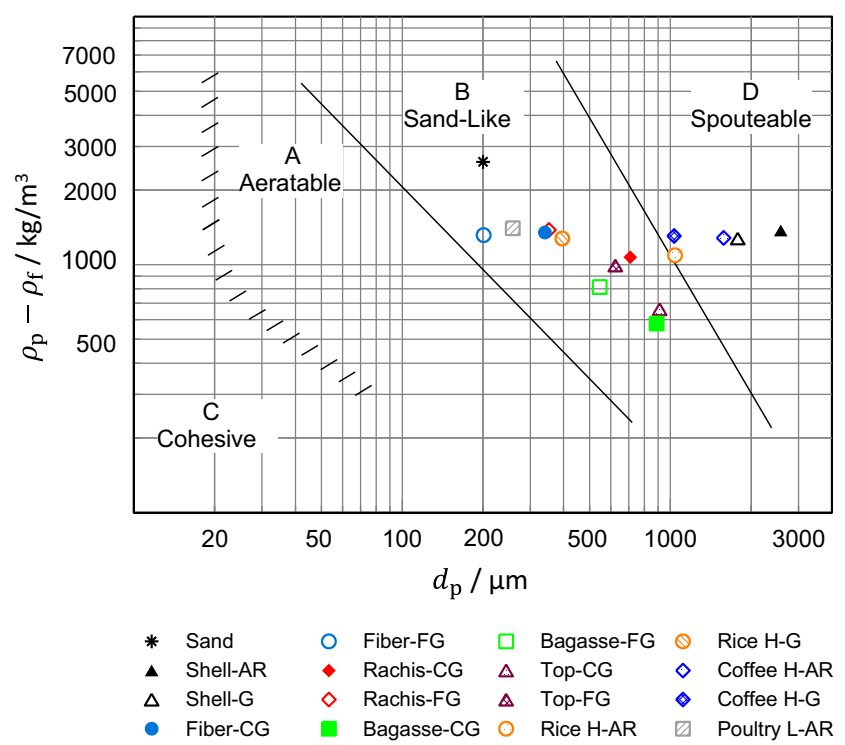

Fig. 2 Geldart classification for the biomass samples used in the present work increased, a stabilization time was given after each increment (between 1 and $2 \mathrm{~min}$ ) before the total pressure drop, and the bed height was measured. At that point, the observed

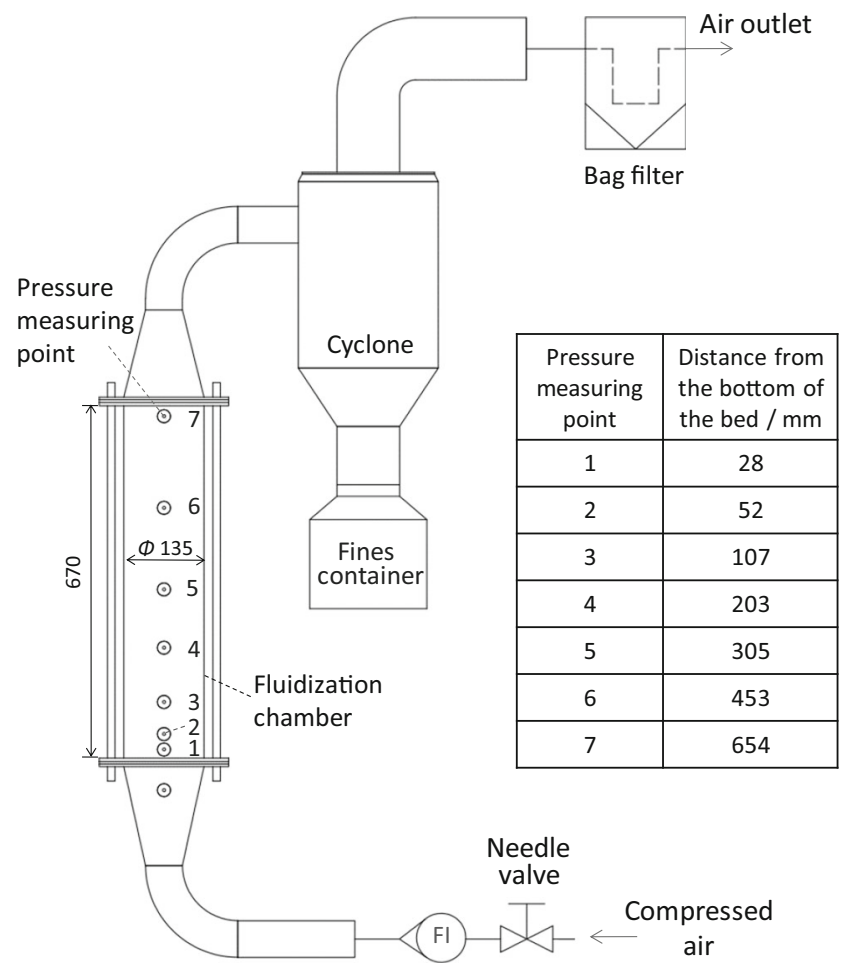

Fig. 3 Experimental unit used for the fluid dynamic characterization of biomass-sand mixtures 
phenomena were reported. Finally, when the maximum achievable flow rate for the experimental unit was reached, the experiment was stopped, and the bed was unloaded from the unit.

\section{Theoretical analysis and calculations}

The typical fluidization curve exhibited for a regular bulk of particles is well known and has often been described in the literature $[18,21]$. This curve, briefly presented in Fig. 4, correlates the total pressure drop of the bed $(\Delta p)$ with the superficial gas velocity $(U)$. A linear steady increment of the pressure drop characterizes the fixed bed state. Beyond a specific point called the initial fluidization velocity $\left(U_{\mathrm{if}}\right)$, the partial fluidization regime is achieved. This transition lasts until the final fluidization velocity $\left(U_{\mathrm{ff}}\right)$ is achieved, then the pressure drop stabilizes around a specific value. The minimum fluidization velocity $\left(U_{\mathrm{mf}}\right)$ is determined as the interception between the linear projections of the lines for fixed and complete fluidized states. At this point, all the particles are essentially supported by the gas stream and the bed voidage corresponds to the loosest packing of the bed $\varepsilon_{\mathrm{mf}}$. If the gas flow is eventually reduced, a gentle tapping of the bed would decrease the voidage to its stable initial value $\varepsilon_{0}$ [37]. A peak in the pressure drop might be observed at the point of minimum fluidization due to bed pre-compaction and the wall effects. This phenomenon is usual for homogeneous beds, but not for binary systems or when handling highly heterogeneous particles. Once the final fluidization velocity $\left(U_{\mathrm{ff}}\right)$ is surpassed, instabilities are likely to appear forming a bubbling fluidization regime. Bubbles are formed at the bottom of the bed and they grow and coalesce while rising axially, to finally burst at the top of the bed throwing up particles to the freeboard. Higher gas velocities result in the formation of a turbulent regime, and as soon as the superficial velocity exceeds the terminal velocity of the particles $\left(U_{t}\right)$, they are carried out of

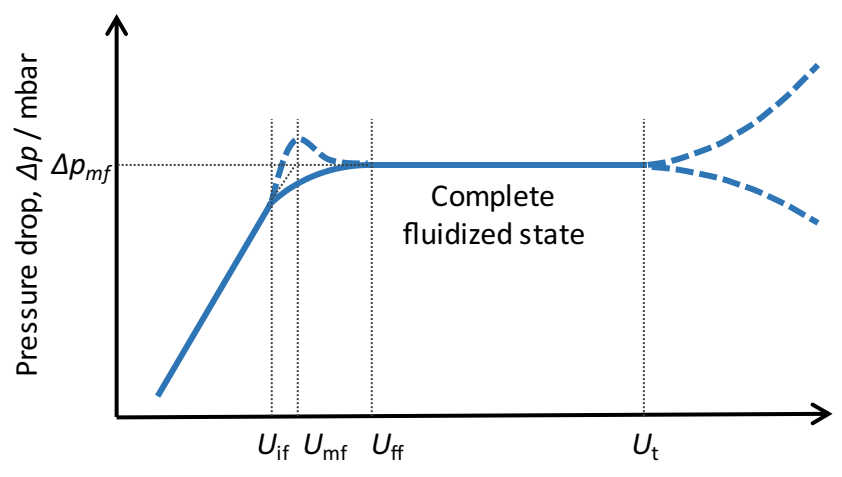

Superficial gas velocity, $U / \mathrm{m} / \mathrm{s}$

Fig. 4 Usual fluidization curve showing the regime transitions from the fixed bed up to pneumatic transport the vessel. Then, the pressure drop can either rise, since the effect of frictional forces grows, or falls, as the mass of particles in the reactor may decrease. Real operation of fluidized beds might differ from the behavior presented in Fig. 4 due to the action of superficial forces not considered in the macroscopic analysis or due to significant variations in the characteristics of the particles.

The equation proposed by Ergun [12] and presented in Eq. (2) expresses the total energy losses in a fixed bed $\Delta p / L$, as the sum of viscous energy losses per unit length (first term in the right side of Eq. (2)) and the kinetic energy losses (second term in the right side of Eq. (2)). This equation conveniently relates the pressure drop through the bed with the physical properties of the gas and the particles that comprise the system. At minimum fluidization velocity $\left(U_{\mathrm{mf}}\right)$, Eq. (2) can be arranged as presented in Eq. (3), which can also be written in terms of $A r$ and $R e_{\mathrm{mf}}$, as shown in Eq. (4). This formulation predicts outstandingly the onset of fluidization for regular (isotropic-shaped), homogeneous bulks of not too small particle size, for which the effect of inter-particle superficial forces is negligible. For those beds, it is also possible to make a good estimation of $\varepsilon_{\mathrm{mf}}$ and $\Phi_{\mathrm{p}}$, so that $U_{\mathrm{mf}}$ can be calculated as proposed by Ergun [12].

$$
\begin{aligned}
& \frac{\Delta p}{L}=150 \frac{\left(1-\varepsilon_{0}\right)^{2}}{\varepsilon_{0}{ }^{3}} \frac{\mu_{f} U}{\left(\Phi_{\mathrm{p}} d_{\mathrm{p}}\right)^{2}}+1.75 \frac{\left(1-\varepsilon_{0}\right)}{\varepsilon_{0}{ }^{3}} \frac{\rho_{\mathrm{f}} U^{2}}{\Phi_{\mathrm{p}} d_{\mathrm{p}}} \\
& \frac{d_{\mathrm{p}}^{3} \rho_{\mathrm{f}}\left(\rho_{\mathrm{p}}-\rho_{\mathrm{f}}\right) g}{\mu_{\mathrm{f}}{ }^{2}}=\frac{150\left(1-\varepsilon_{\mathrm{mf}}\right)}{\varepsilon_{\mathrm{mf}}{ }^{3} \Phi_{\mathrm{p}}{ }^{2}}\left(\frac{d_{\mathrm{p}} U_{\mathrm{mf}} \rho_{\mathrm{f}}}{\mu_{\mathrm{f}}}\right) \\
& +\frac{1.75}{\varepsilon_{\mathrm{mf}}{ }^{3} \Phi_{\mathrm{p}}}\left(\frac{d_{\mathrm{p}} U_{\mathrm{mf}} \rho_{\mathrm{f}}}{\mu_{\mathrm{f}}}\right)^{2} \\
& A r=\frac{150\left(1-\varepsilon_{\mathrm{mf}}\right)}{\varepsilon_{\mathrm{mf}}{ }^{3} \Phi_{\mathrm{p}}{ }^{2}} R e_{\mathrm{mf}}+\frac{1.75}{\varepsilon_{\mathrm{mf}}{ }^{3} \Phi_{\mathrm{p}}} R e_{\mathrm{mf}}^{2}
\end{aligned}
$$

In the case of a bed of irregular particles or for inhomogeneous beds, the use of Ergun's equation is limited due to the difficulty for accurately measuring both bed voidage at minimum fluidization $\left(\varepsilon_{\mathrm{mf}}\right)$ and particle sphericity $\left(\Phi_{\mathrm{p}}\right)$. To overcome this difficulty, Wen and $\mathrm{Yu}$ [39] identified a simplified form of Eq. (4), namely Eq. (5), that allows the estimation of $R e_{\mathrm{mf}}$, and therefore $U_{\mathrm{mf}}$, once the two constants $C_{1}$ and $C_{2}$ are given. The constants are a function of $\varepsilon_{\mathrm{mf}}$ and $\Phi_{\mathrm{p}}$ only, as shown in Eq. 6, and should be found experimentally.

$$
\begin{aligned}
& R e_{\mathrm{mf}}=\left[C_{1}{ }^{2}+C_{2} A r\right]^{0.5}-C_{1} \\
& \frac{1}{\varepsilon_{\mathrm{mf}}^{3} \Phi_{\mathrm{p}}}=C_{1} \quad \frac{\left(1-\varepsilon_{\mathrm{mf}}\right)}{\varepsilon_{\mathrm{mf}}{ }^{3} \Phi_{\mathrm{p}}{ }^{2}}=C_{2}
\end{aligned}
$$

The two constants $C_{1}$ and $C_{2}$ were first estimated by Wen and $\mathrm{Yu}$ [39]. Even though these values showed to be valid for many systems, they are far from being general for all beds; 
therefore, different sets of factors have been proposed by multiple authors. Some of them are summarized by authors who studied different types of mixtures, for example, Gupta et al. [40], Shao et al. [25], Li et al. [41], Fu et al. [28], Karmakar et al. [26], Proenza et al. [27], and Anantharaman et al. [11]. Most of the constants are deduced based on experiments over a limited operation range and for a specific group of systems, for instance, only bagasse, walnut shells, sawdust, or only mixtures with type A or type B sand. Regardless of the values of the constants, many studies agree on the suitability of the methodology and its ability to predict the general trends for pressure drop and minimum fluidization velocity of binary mixtures.

For the present work, 21 different sets of correlation factors $\left(C_{1}\right.$ and $C_{2}$ in Eq. 5) were tested against the experimental results, and these are listed in the supplementary material. The most cited sets in the literature and that presented the lowest relative errors are listed in Table 2.

To evaluate the minimum fluidization using this method, the mixture is treated as a single component; therefore, the effective Archimedes $(A r)$ and the Reynolds $(R e)$ numbers should be used in Eq. (5). These terms are calculated as in Eq. (7) and Eq. (8), using an effective particle density and diameter of the biomass-sand mixture, which can be obtained from Eq. (9) and Eq. (10), respectively [24]. These equations consider $x_{\mathrm{b}}$ and $x_{\mathrm{s}}$ as the weight fraction of sand (s) and biomass (b) in the mixture. It is worth mentioning that this approach shows the best results when one component is dominant or when the properties of the two types of particles are very similar [20]. A better agreement is also found for particles with high sphericity, high bulk density, and low porosity [29, 42].

$$
\begin{aligned}
& A r_{\text {eff }}=\frac{d_{\text {eff }^{3} \rho_{\mathrm{f}}\left(\rho_{\text {eff }}-\rho_{\mathrm{f}}\right) g}}{\mu_{\mathrm{f}}{ }^{2}} \\
& R e_{\mathrm{mf}, \mathrm{eff}}=\frac{d_{\text {eff }} U_{\mathrm{mf}} \rho_{\mathrm{f}}}{\mu_{\mathrm{f}}} \\
& \frac{1}{\rho_{\text {eff }}}=\frac{x_{\mathrm{b}}}{\rho_{\mathrm{b}}}+\frac{x_{\mathrm{s}}}{\rho_{\mathrm{s}}}
\end{aligned}
$$

Table 2 Values of $C_{1}$ and $C_{2}$ to be used in Eq. 5 according to different authors

\begin{tabular}{lll}
\hline Author(s) and reference & $C_{1}$ & $C_{2}$ \\
\hline Wen and Yu [40] & 33.70 & 0.0408 \\
Basu [46] & 30.28 & 0.0460 \\
Grace [44] & 27.20 & 0.0408 \\
Chyangand Huang [45] & 33.30 & 0.0333 \\
Reina et al. [43] & 48.00 & 0.0450 \\
\hline
\end{tabular}

$d_{\mathrm{eff}}=d_{\mathrm{b}} d_{\mathrm{s}}\left[\frac{x_{\mathrm{b}} \rho_{\mathrm{s}}+x_{\mathrm{s}} \rho_{\mathrm{b}}}{x_{\mathrm{b}} \rho_{\mathrm{s}} d_{\mathrm{s}}+x_{\mathrm{s}} \rho_{\mathrm{b}} d_{\mathrm{b}}}\right]$

Relative errors between experimental and predicted minimum fluidization velocities were calculated for each mixture and weight fraction in order to analyze them quantitatively. For the calculation of the relative error in a measurement, the absolute difference between the experimental and predicted value of minimum fluidization velocity is divided into the experimental one. The mean relative error of a group of results is calculated through the arithmetic average. The $\mathrm{SD}(\sigma)$ of the data was calculated with respect to the correlation of interest in order to evaluate its suitability.

\section{Results and discussion}

\subsection{Fluidization of the bed material}

Figure 5 shows the total pressure drop (left hand axis) and the height (right hand axis) of a bed of $2000 \mathrm{~g}$ of silica sand $(A r=542.53)$ against the superficial gas velocity. As expected for a regular bed of B-type particles (as in the case of the sand), the fixed bed regime is characterized by a linear increment of the pressure drop and the subsequent onset of a bubbling regime. From this point, the total pressure drop tends to stabilize; in the present case, the stabilization pressure drop was 15.8 mbar (as indicated in Fig. 5). From the graphical interpolation of the pressure drop data from Fig. 5 (as indicated in Fig. 4), the minimum fluidization velocity should be located at $0.027 \mathrm{~m} / \mathrm{s}$; however, the bed height indicates that the expansion of the bed starts already at $0.025 \mathrm{~m} / \mathrm{s}$. The minimum fluidization velocity $U_{\mathrm{mf}}$ of the sand for the present study will therefore be taken as $0.026 \mathrm{~m} / \mathrm{s}$ (the corresponding $R e_{\mathrm{mf}}$ amounts to 0.2527 ). Below $0.025 \mathrm{~m} / \mathrm{s}$, a fixed bed with a height of about $12.5 \mathrm{~cm}$ is observed; thereafter, the higher

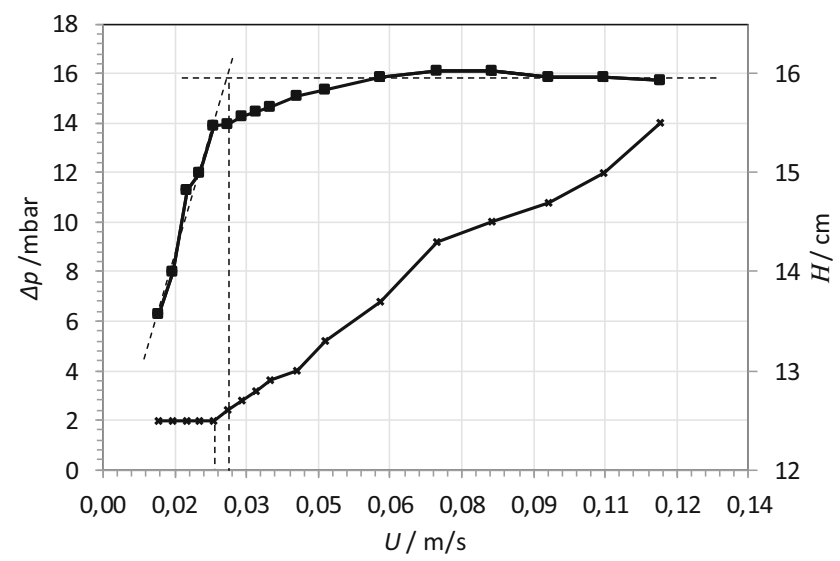

Fig. 5 Fluidization curve and bed expansion for the silica sand used as bed material in the experiments 
the air velocity, the higher the bed height is and the more frequent and larger are the bubbles observed. At an air velocity of $0.116 \mathrm{~m} / \mathrm{s}$, bubbles grow and rise through the bed and vigorous explosions of large bubbles are observed in the surface. A maximum bed height of $15.5 \mathrm{~cm}$ was registered, while the thrown-up particles (splash zone) reached a maximum of $27.0 \mathrm{~cm}$. The fluid dynamic behavior of the sand showed to be regular and homogeneous enough for the fluidization of mixtures with rather small amounts of biomass.

\subsection{Fluidization of the binary mixtures}

From the mixtures tested in the present work, 27 out of 52 exhibited a bubbling behavior. For these mixtures, the minimum fluidization velocity was determined as indicated above. Full results are presented in Table 3, including initial, final, and minimum fluidization velocities, as established in Fig. 4, and the total pressure drop reached at minimum fluidization. The volume fraction of biomass in each mixture $\left(f_{\mathrm{v}}\right)$ and the bed aspect ratio $(H / D)$, defined as the ratio between the bed height at rest and the bed diameter, are presented as well. Figure 6 compares the main results of the mixtures exhibiting bubbling behavior. It can be observed that the volume fraction increases linearly with the increment of the mass fraction as expected, and the variation of $f_{\mathrm{v}}$ is more evident in biomasses with low bulk density, as presented in Fig. 6a. The bed aspect ratio also tends to increase when rising the mass fraction of biomass (Fig. 6b), especially for low bulk density biomasses; however, it was found to be almost constant (around $1 \pm 0.2$ ). Regarding minimum fluidization, some particular cases are remarked. For Fiber-FG 5\%, Bagasse-FG 7\%, Top-FG 3\%, Top-FG 5\%, and Coffee H-AR 3\%, $U_{\text {ff }}$ appeared to be beyond the maximum superficial velocity achievable in the experimental unit $(0.116 \mathrm{~m} / \mathrm{s})$. In these cases, the velocity at which fluidization started (i.e., $U_{\mathrm{if}}$ ) is reported instead of the $U_{\mathrm{mf}}$. Apart from the aforementioned samples, complete fluidization was achieved and the minimum fluidization velocity was clearly identified for all the mixtures. The $U_{\mathrm{mf}}$ of the mixtures
Table 3 Volume fraction $\left(f_{\mathrm{v}}\right)$; bed aspect ratio at rest $(H / D)$; initial $\left(U_{\mathrm{if}}\right)$, final $\left(U_{\mathrm{ff}}\right)$, and minimum $\left(U_{\mathrm{mf}}\right)$ fluidization velocities; and total pressure drop at minimum fluidization $\left(\Delta p_{\mathrm{mf}}\right)$ for the mixtures exhibiting bubbling behavior

\begin{tabular}{|c|c|c|c|c|c|c|}
\hline Mixture & $f_{\mathrm{V}}(\%)$ & $H / D(-)$ & $U_{\text {if }}(\mathrm{m} / \mathrm{s})$ & $U_{\text {if }}(\mathrm{m} / \mathrm{s})$ & $U_{\text {if }}(\mathrm{m} / \mathrm{s})$ & $\Delta p_{\mathrm{mf}}(\mathrm{mbar})$ \\
\hline Shell-AR 3\% & 6.8 & 0.89 & 0.032 & 0.034 & 0.070 & 16.03 \\
\hline Shell-AR 5\% & 11.0 & 0.91 & 0.032 & 0.032 & 0.093 & 15.87 \\
\hline Shell-AR 7\% & 15.0 & 0.93 & 0.029 & 0.032 & 0.093 & 16.35 \\
\hline Shell-AR 10\% & 20.7 & 0.96 & 0.032 & 0.033 & 0.082 & 15.32 \\
\hline Shell-G 3\% & 5.8 & 0.91 & 0.032 & 0.032 & 0.070 & 16.07 \\
\hline Shell-G 5\% & 9.4 & 0.92 & 0.026 & 0.028 & 0.082 & 16.31 \\
\hline Shell-G 7\% & 13.0 & 0.95 & 0.029 & 0.032 & 0.082 & 16.04 \\
\hline Shell-G $10 \%$ & 18.0 & 0.96 & 0.032 & 0.035 & 0.093 & 16.24 \\
\hline Fiber-FG 3\% & 17.8 & 1.04 & 0.035 & 0.036 & 0.093 & 15.36 \\
\hline Fiber-FG 5\% & 26.9 & 1.11 & 0.041 & $0.041^{\mathrm{a}}$ & $>0.116$ & 16.48 \\
\hline Bagasse-FG 3\% & 22.1 & 1.04 & 0.035 & 0.037 & 0.093 & 15.77 \\
\hline Bagasse-FG 5\% & 32.5 & 1.20 & 0.047 & 0.047 & 0.093 & 16.12 \\
\hline Bagasse-FG 7\% & 40.8 & 1.41 & 0.058 & $0.058^{\mathrm{a}}$ & $>0.116$ & 14.86 \\
\hline Top-FG 3\% & 20.2 & 1.03 & 0.035 & $0.035^{\mathrm{a}}$ & $>0.116$ & 14.35 \\
\hline Top-FG 5\% & 30.1 & 1.15 & 0.032 & $0.032^{\mathrm{a}}$ & $>0.116$ & 11.17 \\
\hline Rice H-AR 3\% & 21.9 & 0.96 & 0.026 & 0.038 & 0.105 & 16.35 \\
\hline Rice H-AR 5\% & 32.4 & 1.04 & 0.032 & 0.040 & 0.105 & 16.54 \\
\hline Rice H-G 3\% & 12.9 & 0.95 & 0.029 & 0.035 & 0.082 & 16.16 \\
\hline Rice H-G 5\% & 20.1 & 1.04 & 0.041 & 0.041 & 0.105 & 16.24 \\
\hline Rice H-G 7\% & 26.5 & 1.11 & 0.035 & 0.035 & 0.105 & 16.35 \\
\hline Coffee H-AR 3\% & 17.3 & 0.93 & 0.032 & $0.032^{\mathrm{a}}$ & $>0.116$ & 14.42 \\
\hline Coffee H-G 3\% & 12.4 & 0.96 & 0.032 & 0.032 & 0.105 & 14.92 \\
\hline Coffee H-G 5\% & 19.5 & 1.00 & 0.029 & 0.029 & 0.105 & 15.72 \\
\hline Poultry L-AR 3\% & 7.4 & 0.96 & 0.032 & 0.033 & 0.070 & 16.14 \\
\hline Poultry L-AR 5\% & 11.9 & 0.98 & 0.026 & 0.028 & 0.058 & 16.05 \\
\hline Poultry L-AR 7\% & 16.2 & 1.02 & 0.029 & 0.029 & 0.070 & 15.98 \\
\hline Poultry L-AR $10 \%$ & 22.2 & 1.05 & 0.035 & 0.034 & 0.082 & 16.00 \\
\hline
\end{tabular}

${ }^{\text {a }} U_{\text {if }}$ is registered here instead of $U_{\mathrm{mf}}$ since the fully developed fluidization state was not achieved during the experiment 
Fig. 6 a Volume fraction $\left(f_{\mathrm{v}}\right), \mathbf{b}$ bed aspect ratio at rest $(H / D)$, c minimum fluidization velocity $\left(U_{\mathrm{mf}}\right)$, and $\mathbf{d}$ total pressure drop at minimum fluidization $\left(\Delta p_{\mathrm{mf}}\right)$, for the mixtures exhibiting bubbling behavior, as a function of biomass mass fraction in the mixture
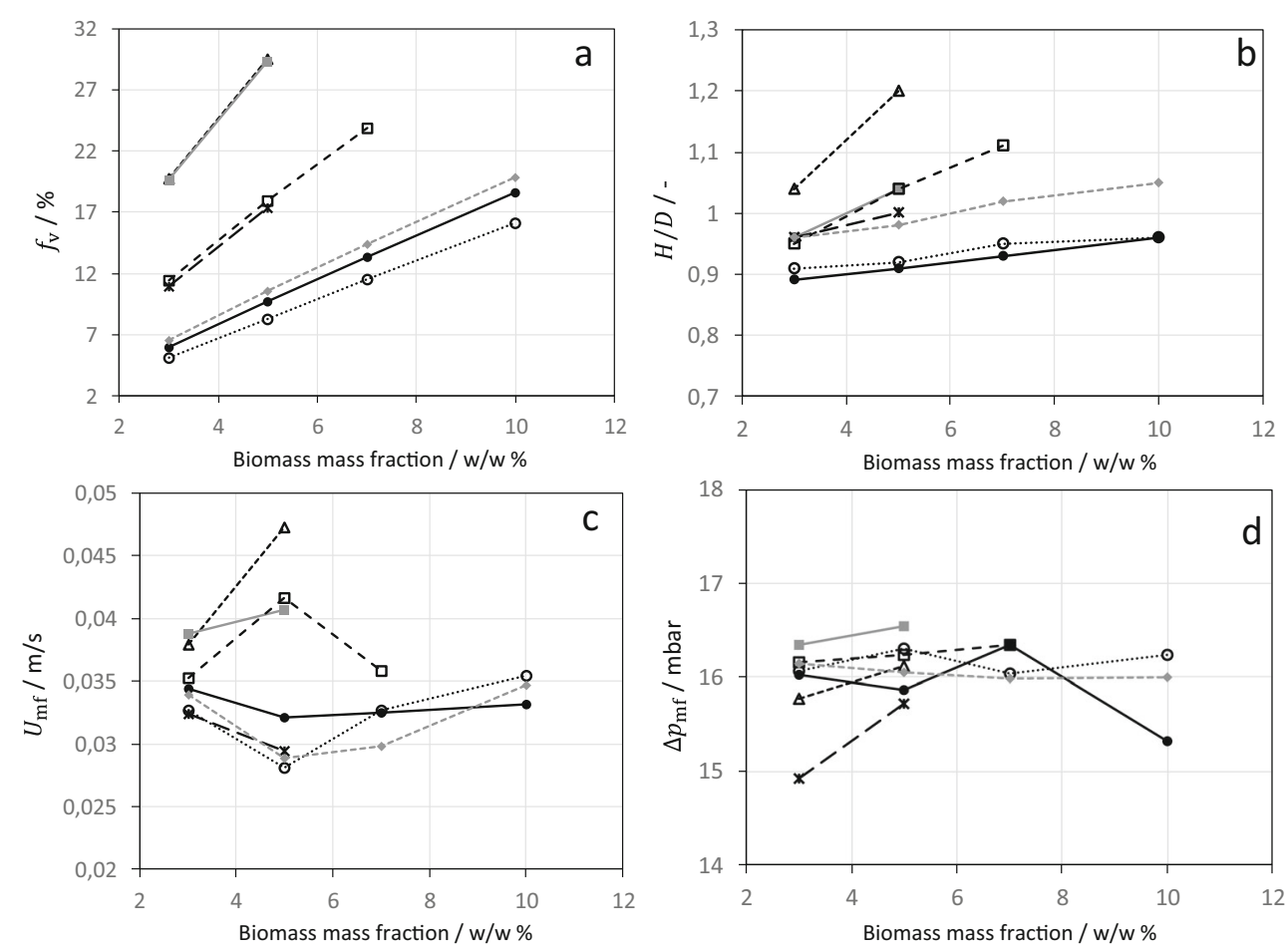

was in all cases higher than that of the pure bed material, i.e., $0.027 \mathrm{~m} / \mathrm{s}$ (Fig. 6c). The total pressure drop at minimum fluidization was found to be constant (15.7 $\pm 1 \mathrm{mbar})$, as shown in Fig. 6d, and is very similar to the one measured for silica sand (15.8 mbar) since the total weight of the mixtures was always the same (2000 g) and the mixture mainly consisted of sand.

The effect of the mass fraction on the minimum fluidization velocity of the mixture was indicated in previous studies [20, $22,25]$. In these works, a rather constant $U_{\mathrm{mf}}$ is observed for low biomass fractions, with a subsequent significant increase when the mass fraction rises. The maximum mass fraction that still allows a constant $U_{\mathrm{mf}}$ and the increase rate of $U_{\mathrm{mf}}$ at higher concentrations varies according to the type of biomass. A similar behavior was observed here for the more regular biomasses, for example, oil palm shell (shell) and poultry litter (Poultry-L). For these particles, Fig. $6 c$ evidences that the increase of mass fraction causes the minimum fluidization velocity to slightly decrease at the beginning, is kept constant for a range of mass fractions, and starts increasing for higher fractions. More irregular biomass particles showed, however, a more variable behavior exhibiting increase of $U_{\mathrm{mf}}$ or impossibility for regular fluidization with already low concentrations. This indicates that besides the mass fraction of biomass in the bed, the particle size and shape of the biomass have a relevant effect on the fluidization of the mixtures that will be further discussed below.

The effect of the biomass mass fraction in the bed can be better explained when analyzing the fluidization curves of oil palm shell and poultry litter mixtures. These mixtures showed the most stable fluidization behavior since even the mixtures with the highest biomass fractions tested showed a regular bubbling pattern and a homogeneous mixing in the entire bed. These biomasses are characterized by sphericities higher than 0.69 and bulk densities higher than $544 \mathrm{~kg} / \mathrm{m}^{3}$; however, they are different in size.

Figure $7 \mathrm{a}$ shows the fluidization curves of Shell-AR in mixtures of different biomass mass fractions. The curves for $3 \% \mathrm{w} / \mathrm{w}, 5 \% \mathrm{w} / \mathrm{w}$, and $7 \% \mathrm{w} / \mathrm{w}$ stabilized at a similar value of total pressure drop (around 16 mbar), but the stabilization requires higher velocities when the fraction of biomass in the bed is larger. The larger the amount of biomass in the 

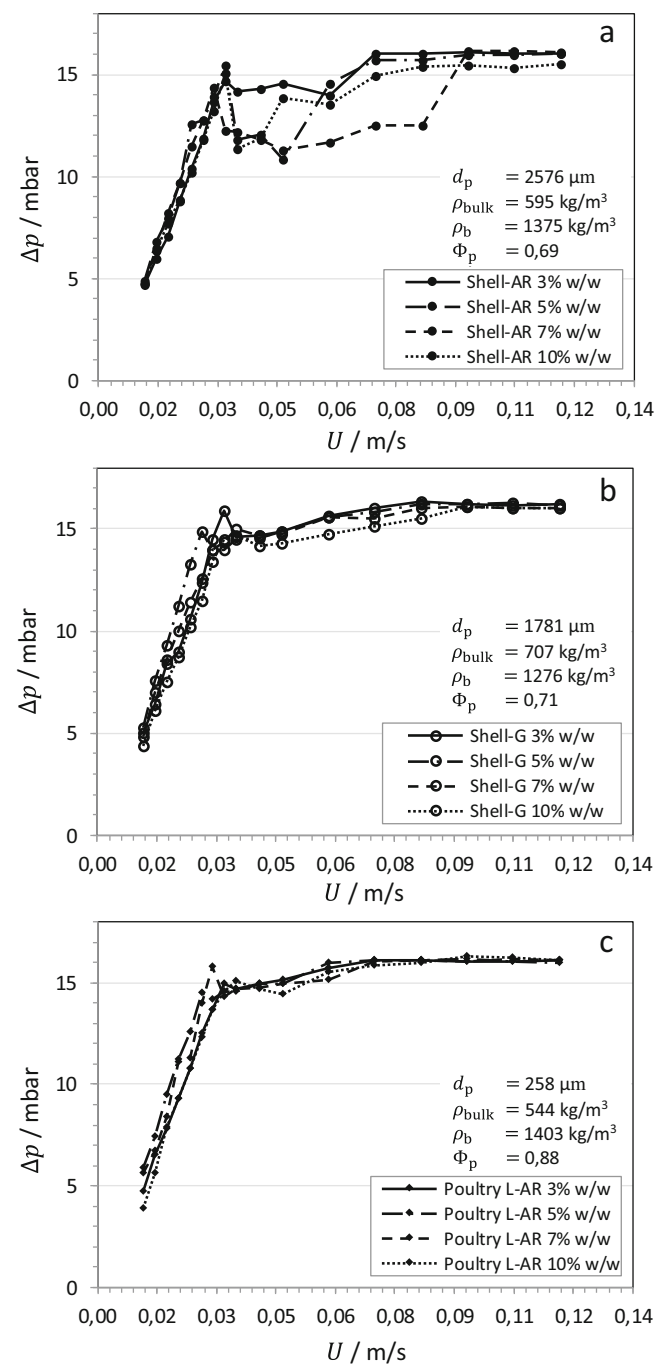

Fig. 7 Fluidization curves of mixtures at different biomass mass fractions: a oil palm shell as received (Shell-AR); b oil palm shell ground (Shell-G); c poultry litter as received (Poultry L-AR)

mixture, the wider are also the fluctuations of the pressure drop before reaching a stable fluidization. The mixture of $10 \% \mathrm{w} / \mathrm{w}$ Shell-AR follows a similar tendency but stabilized at a slightly lower pressure drop, probably due to the small differences in the sample mass. The full stabilization of this mixture requires a higher fluidization velocity as well. The minimum fluidization velocity is very similar for the four mixtures (between 0.032 and $0.035 \mathrm{~m} / \mathrm{s}$ ), and about $30 \%$ higher than the one of the bed material. As presented in Fig. 3, Shell-AR particles are a clear prototype of D-type particles, usually too large to be fluidized and used therefore in spouted beds, although the mixtures with sand achieve a very satisfactory fluidization. The approximately constant minimum fluidization velocity $U_{\mathrm{mf}}$ for these samples indicate that the mass fraction of biomass could still be increased without considerably affecting the fluidization behavior. This means that the mass fraction at which the $U_{\mathrm{mf}}$ starts sharply increasing was not reached. Figure $7 \mathrm{~b}$ presents the fluidization curves for Shell-G mixtures at 3\% w/w, 5\% w/w, 7\% w/w, and $10 \% \mathrm{w} / \mathrm{w}$. These particles have a mean size of approximately one half compared with Shell-AR but are very similar in all other properties. These mixtures also exhibit less notorious fluctuations of the pressure drop, before reaching stable fluidization, that increase only slightly with the rising of mass fraction. The fluidization curves of Poultry L-AR at $3 \% \mathrm{w} / \mathrm{w}$, $5 \% \mathrm{w} / \mathrm{w}, 7 \% \mathrm{w} / \mathrm{w}$, and $10 \% \mathrm{w} / \mathrm{w}$ are shown in Fig. $7 \mathrm{c}$. Particles of Poultry L-AR have a comparatively smaller mean particle size and are slightly more rounded and dense $\left(\Phi_{\mathrm{p}}=\right.$ 0.88 and $\rho_{\mathrm{p}}=1403 \mathrm{~kg} / \mathrm{m}^{3}$ ) than the two samples of shell particles (as received and ground). They are classified as Btype particles and are more likely to be easily fluidized. These mixtures exhibited high stability even in the transient fluidization zone. The increase in the velocity of stabilization as a function of the mass fraction, as observed in larger particles (Shell-AR and Shell-G), is not appreciable here. All mixtures achieve a stable fluidization at a similar velocity (as shown in Fig. 6c). In addition, the minimum fluidization velocities resulted to be very similar to that of the bed material. According to previous experiences in the field [20,22, 25], it is probable that concentrations beyond $10 \% \mathrm{w} / \mathrm{w}$ would experience an increase in the minimum fluidization velocity.

A detailed analysis of fluidization curves allows a better understanding of the effect of the biomass particle's properties aside from its concentration in the bed. The influence of the mean particle size of biomass was analyzed comparing fluidization curves of mixtures containing the same type of biomass in the same concentration but a notable different mean particle size. Figure 8 presents the comparison between ShellAR (as received) and Shell-G (ground) at the four different concentrations tested. As mentioned above, these particles have comparatively high sphericities and exhibited good behavior for the range of mass fractions tested. Even though the only significant difference between the two samples is the particle size, the differences between the curves are evident. The mixtures containing finer biomass particles reach a uniformly fluidized state very smoothly, while larger particles cause the whole bed to behave irregularly. In some cases, the total pressure drop in the bed indicates a transitory fluidization in the presence of channels.

The influence of the mean particle size can also be observed in less spherical particles. Figure 9 compares pairs of fluidization curves for mixtures containing the same biomass type in the same mass fraction, so that the most significant difference between the two curves is the mean particle size of the biomass particles. Four cases were selected: bagasse 3\%, rice husk $5 \%$, rice husk $3 \%$, and coffee husk $3 \%$. These particles have comparatively low sphericities than those presented in Fig. 8, ranging from 0.36 to 0.55. Particles of BagasseFG are around $40 \%$ smaller and only slightly more rounded than particles of Bagasse-CG, but the differences in the fluid dynamic behavior are noticeable even for the mixture with $3 \%$ 

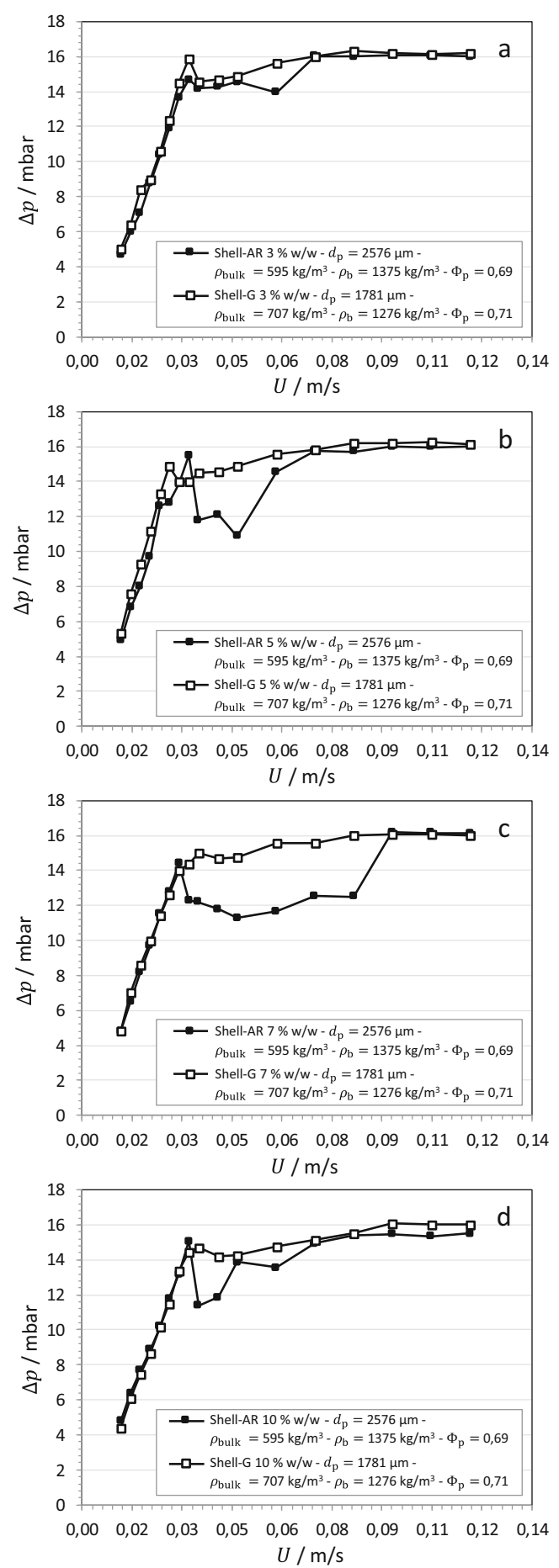

Fig. 8 Fluidization curves of oil palm shell for different mass fractions in sand: a $3 \%$, b $5 \%$, c $7 \%$, and d $10 \%$. Influence of the particle size of the biomass on the transient fluidization: Shell-AR $(2576 \mu \mathrm{m})$ and Shell-G $(1781 \mu \mathrm{m})$

w/w bagasse, as shown in Fig. 9a. Bagasse particles have a particle density lower than other biomasses used in the present study; this makes the particles less similar to those of the bed material and, therefore, less likely to achieve a regular fluidization. They are still classified as B particles but located in a
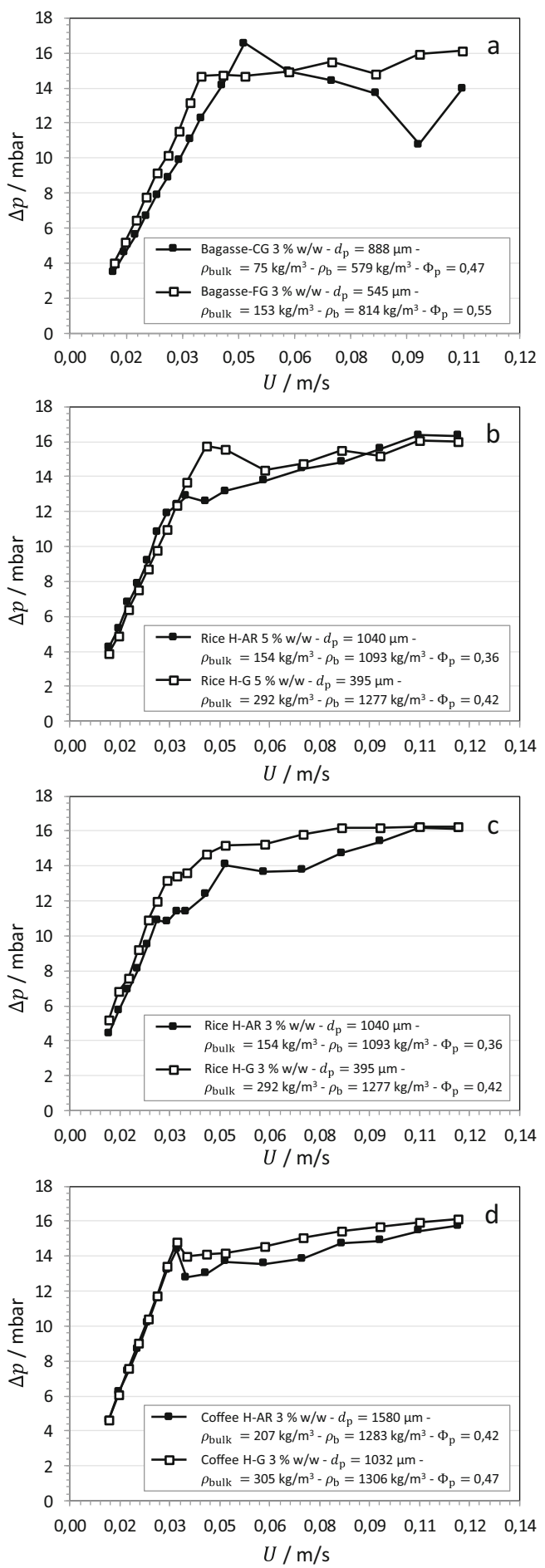

Fig. 9 Fluidization curves of a Bagasse 3\%, b Rice H 5\%, c Rice H 3\%, and d Coffee $\mathrm{H} 3 \%$. Influence of the particle size of the biomass on the transient fluidization

different zone on Geldart diagram (see Fig. 2). As shown in Fig. 9b, while the total pressure drop for Rice H-G 5\% rapidly reaches a final pressure drop and then fluctuates after achieving the minimum fluidization velocity (at $0.041 \mathrm{~m} / \mathrm{s}$ ), the pressure drop of Rice H-AR 5\% shows a steady increment from 
the initial fluidization velocity (at $0.032 \mathrm{~m} / \mathrm{s}$ ) until the transient fluidization state is reached at $0.105 \mathrm{~m} / \mathrm{s}$. For this mixture, the minimum fluidization velocity is $0.0407 \mathrm{~m} / \mathrm{s}$. While Rice $\mathrm{H}-\mathrm{G}$ particles are typical B-type particles and easy to fluidize, Rice H-AR particles are much larger in size, thus they can rather be classified between B-type and D-type particles. Since the differences in density and sphericity of the particles and mass fraction of biomass in the bed can be considered small, the size of the particle is mainly responsible for the divergence in the fluid dynamic behavior of these samples. The influence of the sphericity can, however, not be fully neglected (as it will be presented further on), the mixtures of H-AR (sphericity 0.36) need in general a higher velocity to reach a stable regular fluidization, and the characteristic salient point is not always found in the progression of the pressure drop. Attenuated pressure fluctuations are observed for a lower mass fraction (3\% w/w in Fig. 9c), but the general tendency is maintained. Similar observations were obtained for Coffee H-AR 3\% w/w and Coffee H-G 3\% w/w (Fig. 9d). Differences between these two mixtures are, however, less noticeable. This can be attributed to the fact that the sizes do not differ from each other as much as in the rice husk samples and both can be classified as D-type particles. As presented in Fig. 9d, the steady increment of the pressure drop is observed in both samples of Coffee $\mathrm{H}$ (Coffee H-AR 3\% and Coffee H-G 3\%) after reaching the minimum fluidization velocity of the mixture. Once again, the smaller the mean particle size of the biomass, the more stable the fluidization is after overcoming the initial fluidization velocity. Only small differences were observed between the fluidization curves of the mixtures once the final fluidization velocity is surpassed, regardless of the particle size.

As described above, different types of biomass exhibit also very different values of sphericity, which appears to affect the fluid dynamic behavior of the mixture as well. Figure 10 presents two examples of this influence, comparing on the one hand the fluidization curves of Shell-G and Coffee H-AR and on the other Poultry L-AR and Fiber-FG. These are particles with similar mean particle size and particle density, but notable different shapes. In both cases, the more regular particles (higher sphericity) can be fluidized even with high mass fractions, while particles of low sphericity are prone to exhibit an irregular fluidization or cannot be fluidized at all. It should be noted at this point that the reduction in the particle size often leads to an increase in the particle sphericity, especially in the case of very irregular particles. This can be seen in Figs. 8 and 9 for oil palm shells, where the reduction in size increases only slightly the sphericity since the particles are already very regular. In contrast, for particles such as bagasse, rice husk, and coffee husk, the reduction in size has a more evident effect on the increase of sphericity. Sphericity values for more irregular particles such as fibers are given in Table 1 . The effect on the fluid dynamic behavior of the bed might therefore be a combination of a decrease in the particle size and an increase in the sphericity.

Since the two most relevant physical properties of the particles are inherent to the Geldart classification, other possible interdependencies among particle properties are implicit in this classification. These interdependencies are, for example, increase of bulk density with both, the reduction in size and
Fig. 10 Fluidization curves of a Shell-G, b Coffee H-AR, c Poultry L-AR, and d Fiber-FG. Influence of the sphericity of biomass particles on the transient fluidization
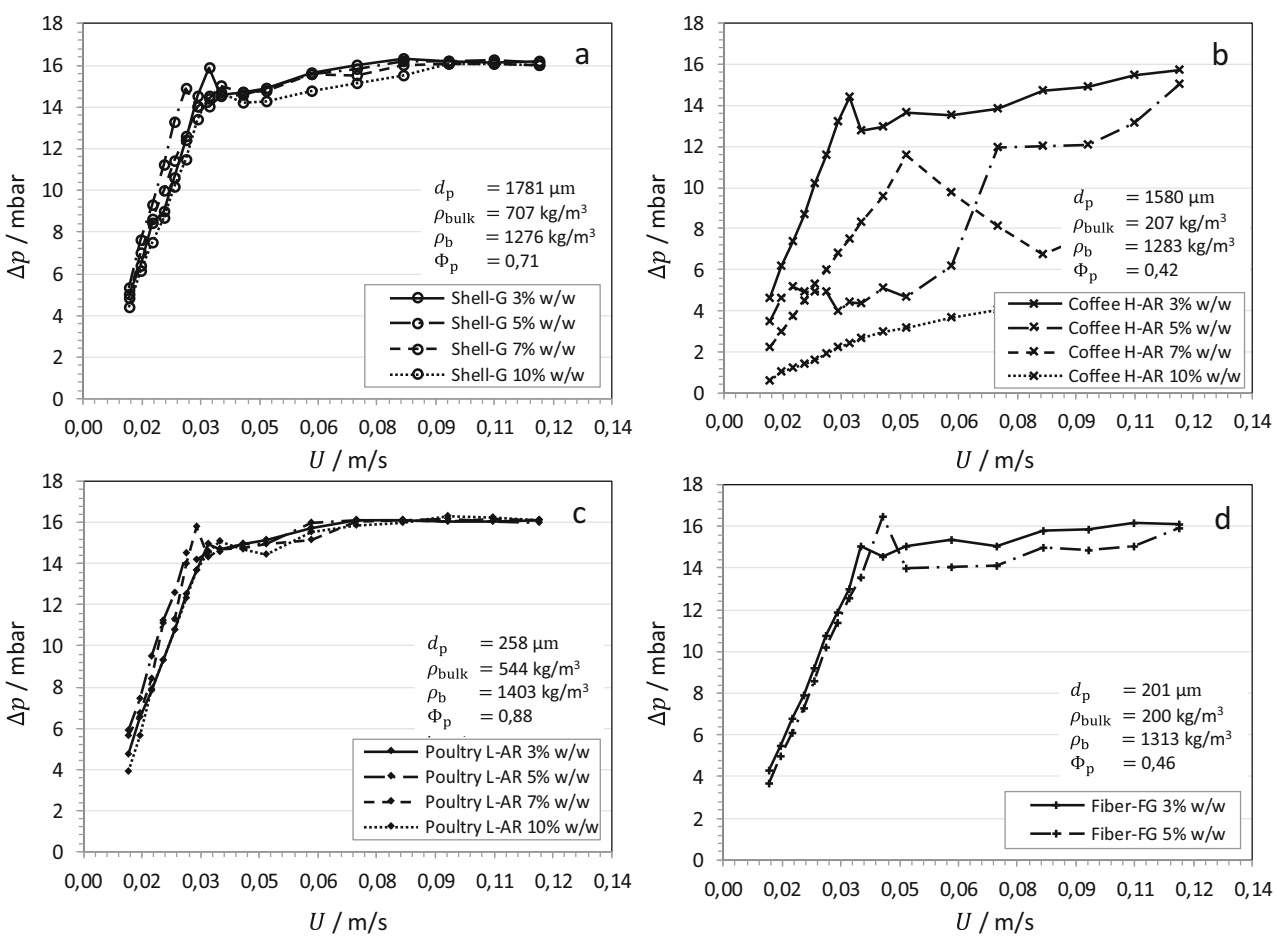
the increase of particle density, and increase of sphericity with the decrease of size. This classification might therefore be a good indication for the behavior of the biomass particles in the mixture.

\subsection{Prediction of minimum fluidization velocities of binary mixtures}

Figure 11 plots the minimum fluidization velocities obtained from experiments (markers), as well as the predictions when using the selected correlations factors listed in Table 2 (lines). A plot is depicted for each of the four biomass fractions tested. In all cases, the minimum fluidization of the bed material is also plotted as reference. The five different sets of factors selected follow a similar increase with the Ar number, which is also observed in the experimental results. Even though the correlations properly approach the minimum fluidization velocities of the mixtures, there is no correlation able to predict the behavior of all the mixtures and the dispersion of data is considerable. However, some sets of factors seem to be more appropriate for some groups of mixtures.
The behavior of the bed material, sand, suits the prediction of Reina et al. [42]. The mixtures of $3 \% \mathrm{w} / \mathrm{w}$ biomass fit within the limits demarcated by Grace [43] and Chyang and Huang [44], and are contiguous to the line of Wen and $\mathrm{Yu}$ [39]. A further increase of the biomass concentration causes the mixtures of Shell-AR, Shell-G, Top-FG, Poultry L-AR, as well as Coffee H-G to move closer to the predictions of Chyang and Huang [44] and Reina et al. [42], while Grace [43] overestimates the Reynolds number at the minimum fluidization of rice husk mixtures and Basu [45] underestimates those for Fiber-FG and Bagasse-FG. For the mixtures of $10 \%$ w/w mass fraction, the correlation of Wen and $\mathrm{Yu}$ [39] provides the best results for Poultry L-AR, while that of Chyang and Huang [44] and Reina et al. [42] still work well for ShellAR and Shell-G mixtures. The largest deviation is observed for Bagasse-FG 7\% w/w, as shown in Fig. 11c, where no correlation allows a proper estimation of the $R e_{\mathrm{mf}}$. This could be partially due to the fact that Bagasse-FG 7\% w/w presents the highest volume fraction of biomass $(40.8 \% \mathrm{v} / \mathrm{v})$ and the highest bed aspect ratio (1.41) of all the mixtures studied here, as shown in Table 3 . In fact, $U_{\mathrm{mf}}$ and $U_{\mathrm{ff}}$ are expected to rise
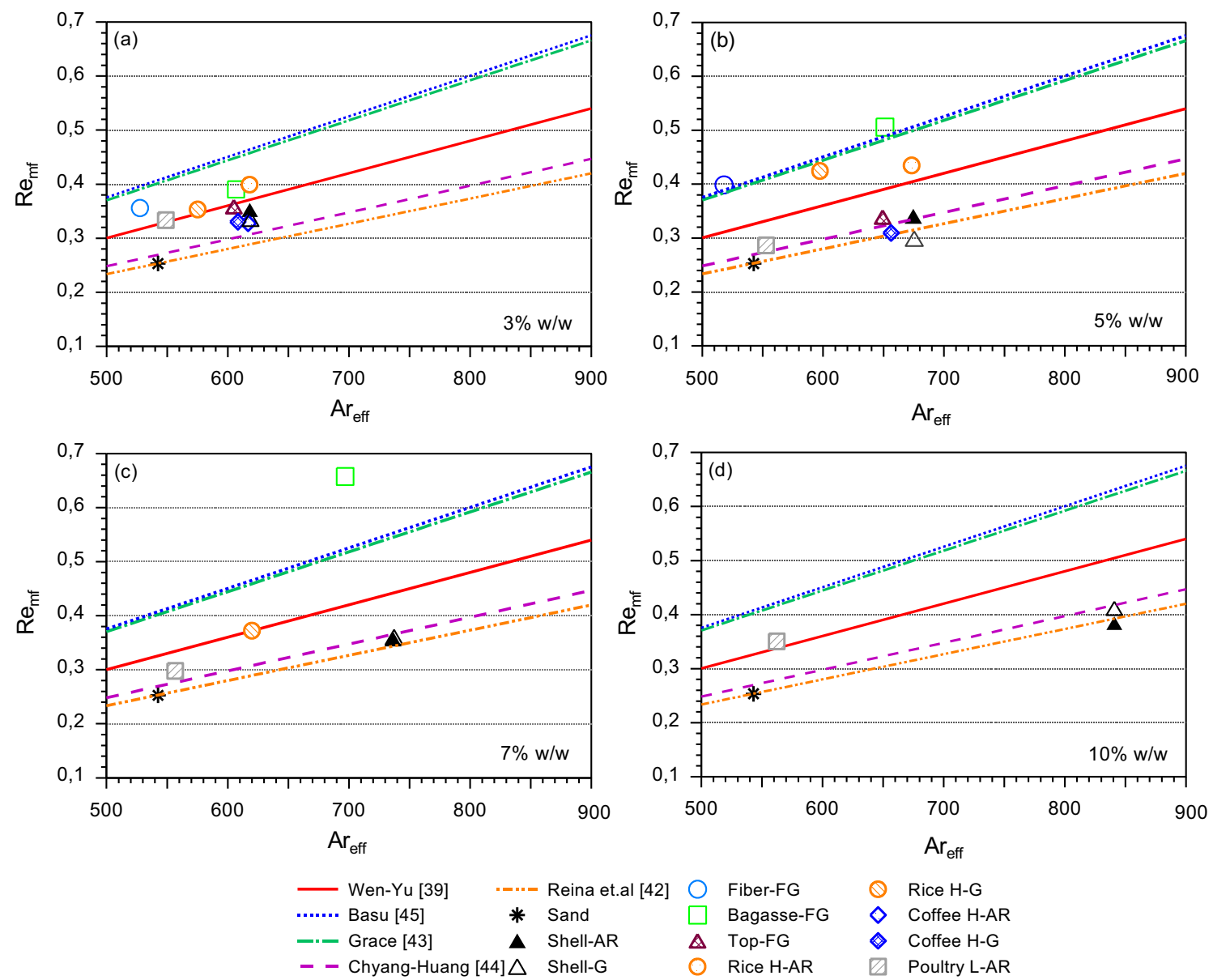

Fig. 11 Comparison between experimental and predicted values of $R e_{\mathrm{mf}} \mathrm{using}$ the correlation factors of Table 2 for mixtures of a $3 \% \mathrm{w} / \mathrm{w}, \mathbf{b} 5 \% \mathrm{w} / \mathrm{w}$, $\mathbf{c}$ $7 \% \mathrm{w} / \mathrm{w}$, and $\mathbf{d} 10 \% \mathrm{w} / \mathrm{w}$ of biomass in sand 
very sharply for volume concentrations beyond $30-50 \% \mathrm{w} / \mathrm{w}$ in binary mixtures $[21,22]$.

Considering groups of results according to the mass fraction of biomass in the bed, the lowest mean relative errors were found using the correlation of Wen and $\mathrm{Yu}$ [39] for the mixtures with $3 \% \mathrm{w} / \mathrm{w}$ biomass (relative error $6.9 \%$ ) and the correlation of Chyang and Huang [44] for the mixtures of 5\% $\mathrm{w} / \mathrm{w}, 7 \% \mathrm{w} / \mathrm{w}$, and $10 \% \mathrm{w} / \mathrm{w}$ biomass (relative error of $16.8 \%$, $14.9 \%$, and $10.4 \%$, respectively). The lowest SDs $(\sigma)$ were obtained for the correlations of Wen and $\mathrm{Yu}$ [39] for biomass concentrations below or equal to $7 \% \mathrm{w} / \mathrm{w}(\sigma=4.4 \%, 8.3 \%$, and $13.1 \%$, respectively). For mixtures of $10 \% \mathrm{w} / \mathrm{w}$ biomass, the correlation of Chyang and Huang [44] provides the lowest deviation $(\sigma=2.9 \%)$.

As mentioned above, the physical properties of the biomass particles (size, density, sphericity) also have relevant effects on the minimum fluidization velocity and fluid dynamic behavior of the mixture. Therefore, the biomass concentration in the mixture is not sufficient for the proper adjustment of the correlation. The minimum fluidization velocity of the mixtures can in fact be satisfactorily predicted with a mean relative error below $10 \%$ (considerably lower than in other studies [46]) when properly identifying the most suitable correlation for the specific Geldart group of the corresponding biomass particle. This can be observed in Fig. 12, which shows the relative error for four Geldart sub-classes and the different correlations analyzed in the present work. Only the error for Bagasse-FG 7\% could not be minimized. As shown in the figure, the correlation proposed by Wen and $\mathrm{Yu}$ [39] achieves the lowest relative error for the mixtures of B-type particles with a mean relative error of $8.7 \%$. Minimum fluidization velocities of D-type particles mixtures correlate well with

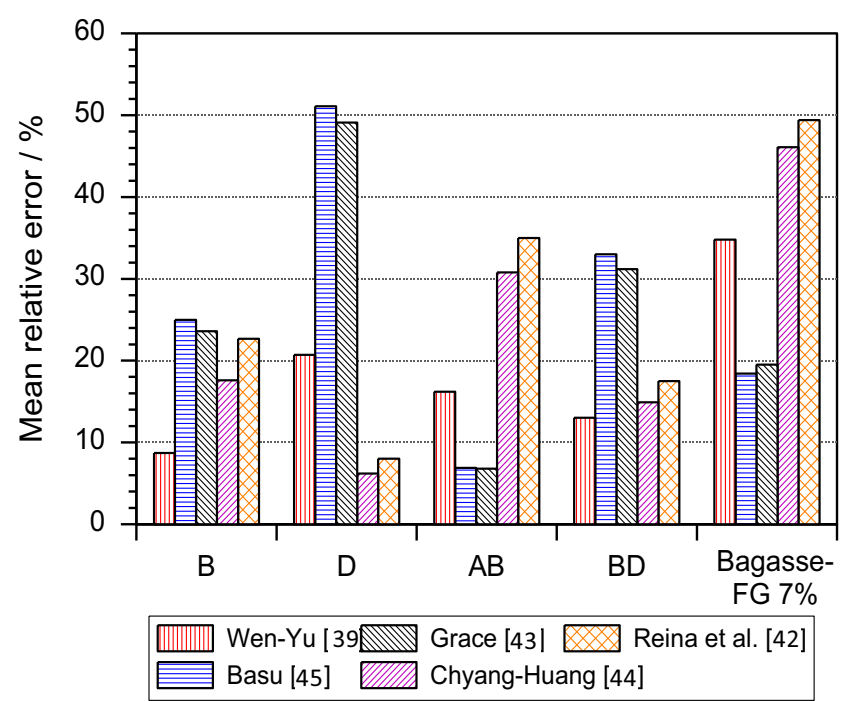

Fig. 12 Mean relative errors between experimental and predicted minimum fluidization velocities using correlations factors listed in Table 2 and classifying their suitability according to the Geldart classification of the biomass particles the predictions of Chyang and Huang [44] and Reina et al. [42] (mean relative error of $6.2 \%$ and $8.0 \%$, respectively). As expected, the correlation proposed by Grace [43] fits satisfactorily for finer AB-type particles, with a mean relative error of $6.8 \%$, and the correlation of Basu [45] achieves the same low errors for this kind of particles. In addition, the correlation proposed by Wen and $\mathrm{Yu}$ [39] makes the closest prediction for BD-type particles, with a mean relative error of $13.0 \%$. Since this is not as low as desirable, further research on correlations for these types of particles is suggested. Finally, the correlation proposed by Basu [45] seems to be the best for capturing the behavior of Bagasse-FG 7\% (B-type particle), but it is still not satisfactory with a mean relative error of $18.4 \%$.

These results show that low relative errors in the prediction of the minimum fluidization velocity of highly heterogeneous binary systems are achieved when the appropriate correlation is selected, according to the corresponding Geldart classification of the biomass particles (lesser component). Nevertheless, alternative correlations or refinements must be carried out for BD-type particles and for mixtures that exhibit bed aspect ratios considerably higher than 1.0 or biomass volume fractions higher than $35 \%$. A correct classification of the biomass particles relies on the capacity of accurately determining their physical properties such as size, density, and sphericity. The results presented here are extended to binary mixtures including particles different from biomass. The study of binary mixtures is particularly appealing, including char particles, which are the actual mixtures processed in thermochemical reactors.

\section{Conclusions}

Experimental study of biomass-sand mixtures at different mass concentrations, together with a careful reconsideration of physical properties of the biomass particles, led to a convenient approach for the estimation of their minimum fluidization velocity. Mass fraction of biomass in the bed, particle size, and sphericity of the biomass were observed to have significant effects on the fluidization of the mixtures. For similar total mass in the bed, the pressure drop stabilizes at nearly the same value, regardless of the mass fraction of biomass in the mixture. However, stabilization requires higher gas velocities when the fraction of biomass in the bed is larger. Larger amounts of biomass in the mixture also cause wider pressure fluctuations before reaching stable fluidization. This means that, although the minimum fluidization velocities have slight differences, a stable fluidization is more feasible for low mass fractions of biomass.

For similar biomass type and biomass weight fractions, reducing the particle size allows a smoother transition to the fluidized state, that is, the bed behaves more like a homogeneous bed. However, it must be pointed out that the sphericity 
of biomass particles increases with the reduction of the particle size, thus, the effect on the fluid dynamic behavior can be a combination of the change in these two properties. Larger and less spherical biomass particles and the increase of the biomass fraction hinder the uniform fluidization of the binary bed. This means that a wider transition zone and larger pressure drop fluctuations are observed and that higher velocities are required to reach stable fluidization. In the biomass studied here, oil palm shell and poultry litter exhibited a homogeneous bubbling behavior for the full range of concentrations under study, while for flaky (rice husk and coffee husk), fibrous (oil palm fiber), and flat (sugarcane bagasse and sugarcane top) types of particles, a stable fluidization was only reachable up to $7 \% \mathrm{w} / \mathrm{w}$ biomass mass fractions in sand.

The use of correlations based on pressure drop allowed the prediction of the minimum fluidization velocity of the mixtures with mean relative errors below $10 \%$. These low deviations were achieved by identifying appropriate correlations depending on the Geldart classification of each biomass, i.e., Grace [43] and Basu [45] for AB-type particles, Wen and $\mathrm{Yu}$ [39] for B-type particles, and Chyang and Huang [44] and Reina et al. [42] for D-type particles. The accuracy of prediction can be negatively affected by biomass volume fractions in mixtures higher than $35 \% \mathrm{v} / \mathrm{v}$ and bed aspect ratio at rest highly deviated from the unity.

The detailed analysis of the relations between the selected parameters (particle size, density, sphericity of the biomass particles, mass fraction of the biomass in the mixture, and Geldart classification) with the fluidynamic behavior of the mixture (here the $U_{\mathrm{mf}}$, in particular) deserves good attention. This perspective may open new possibilities toward the generalization of correlations based on pressure drop and helps in improving the accuracy of prediction of the minimum fluidization velocity in highly heterogeneous mixtures. Moreover, if the change of the physical properties of the biomass during thermal processing is known, modifications in their fluid dynamic behavior could be better predicted. Further work will therefore include the accurate determination of char physical properties and fluid dynamic study of char-sand mixtures.

Supplementary Information The online version contains supplementary material available at https://doi.org/10.1007/s13399-020-01189-9.

Acknowledgments The authors gratefully acknowledge the financial support of the Research Vice-President's Office of the Universidad Nacional de Colombia (Project \# 28168) and the Administrative Department of Science, Technology and Innovation (Colciencias) through the programs "Tiempo de volver" (Call \# 656 of 2014) and Young Researchers 2015.

Authors' contributions D.C.G.-P.: conceptualization, methodology, formal analysis, writing - review and editing, visualization, supervision.

L.E.C.-M.: formal analysis, investigation, writing — original draft, visualization.

S.L.R.-P.: writing - review and editing, visualization, supervision, project administration.
Funding Open Access funding provided by Chalmers University of Technology. Research Vice-President's Office of the Universidad Nacional de Colombia (Project \# 28168) and the Administrative Department of Science, Technology and Innovation (Colciencias) through the programs "Tiempo de volver" (Call \# 656 of 2014) and "Young Researchers 2015."

Data availability Data available on request.

\section{Compliance with ethical standards}

Conflict of interest The authors declare that they have no competing interests.

Code availability Not applicable.

\section{Nomenclature}

$A r$, Archimedes number

$A r_{e f f}$, Effective Archimedes number

$C$, Constant in Eq. 5

$D$, Bed diameter (m)

$d_{b}$, Mean particle size of biomass particles $(\mathrm{m})$

$d_{e f f}$ Effective mean particle size of the mixture (m)

$d_{p}$, Mean particle size $(\mathrm{m})$

$d_{s}$, Mean particle size of sand particles (m)

$f_{v}$, Volume fraction of biomass in the mixture (\%)

$H$, Bed height (m)

$L$, Height difference (in Eq. 2) (m)

$P_{e}$, Particle perimeter $(\mathrm{m})$

$P_{o}$, Atmospheric pressure $(\mathrm{Pa})$

$R e$, Reynolds number

$R e_{m f}$, Reynolds number at minimum fluidization

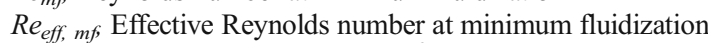

$S_{p}$, Projected area of the particle $\left(\mathrm{m}^{2}\right)$

$U$, Superficial gas velocity $(\mathrm{m} / \mathrm{s})$

$U_{f ;}$, Final fluidization velocity $(\mathrm{m} / \mathrm{s})$

$U_{i f}$, Initial fluidization velocity $(\mathrm{m} / \mathrm{s})$

$U_{m f}$, Minimum fluidization velocity $(\mathrm{m} / \mathrm{s})$

$U_{t}$, Terminal velocity $(\mathrm{m} / \mathrm{s})$

$w_{b}$, Weight of the biomass particles $(\mathrm{kg})$

$w_{s}$, Weight of the sand particles $(\mathrm{kg})$

$x_{b}$, Weight fraction of biomass in mixture

$x_{s}$, Weight fraction of sand in mixture

$\Delta p$, Pressure drop (mbar)

$\Delta p_{m}$, Pressure drop at minimum fluidization (mbar)

$\varepsilon_{0}$, Void fraction at rest

$\varepsilon_{m f}$, Void fraction at minimum fluidization

$\mu_{f}$, Gas viscosity (Pa s)

$\rho_{b}$, Particle density of the biomass particles $\left(\mathrm{kg} / \mathrm{m}^{3}\right)$

$\rho_{\text {bulk }}$, Bulk density $\left(\mathrm{kg} / \mathrm{m}^{3}\right)$

$\rho_{f}$, Gas density $\left(\mathrm{kg} / \mathrm{m}^{3}\right)$

$\rho_{e f f}$, Effective density of the mixture $\left(\mathrm{kg} / \mathrm{m}^{3}\right)$

$\rho_{p}$, Particle density $\left(\mathrm{kg} / \mathrm{m}^{3}\right)$

$\rho_{s}$, Density of the sand particles $\left(\mathrm{kg} / \mathrm{m}^{3}\right)$

$\sigma$, SD $(\%)$

$\Phi_{p}$, Sphericity

\section{Designation of the biomass samples}

Bagasse-CG, Sugarcane bagasse coarsely ground

Bagasse- $F G$, Sugarcane bagasse finely ground

Coffee $H-A R$, Coffee husk as received

Coffee $H-G$, Coffee husk ground

Fiber-CG, Oil palm fiber coarsely ground

Fiber-FG, Oil palm fiber finely ground 
Poultry L-AR, Poultry litter as received Rachis-CG, Oil palm rachis coarsely ground Rachis-FG, Oil palm rachis finely ground Rice $H-A R$, Rice husk as received Rice $H-G$, Rice husk ground Shell-AR, Oil palm shell as received Shell-G, Oil palm shell ground Top-CG, Sugarcane top coarsely ground Top- $F G$, Sugarcane top finely ground

Open Access This article is licensed under a Creative Commons Attribution 4.0 International License, which permits use, sharing, adaptation, distribution and reproduction in any medium or format, as long as you give appropriate credit to the original author(s) and the source, provide a link to the Creative Commons licence, and indicate if changes were made. The images or other third party material in this article are included in the article's Creative Commons licence, unless indicated otherwise in a credit line to the material. If material is not included in the article's Creative Commons licence and your intended use is not permitted by statutory regulation or exceeds the permitted use, you will need to obtain permission directly from the copyright holder. To view a copy of this licence, visit http://creativecommons.org/licenses/by/4.0/.

\section{References}

1. REN21 (2020) Renewable Energy Policy Network. Secretariat for the 21st Century, Renewables, (2020) Global status report. France, Paris

2. Gonzalez-Salazar MA, Morini M, Pinelli M, Spina PR, Venturini M, Finkenrath M, Poganietz WR (2014) Methodology for biomass energy potential estimation: projections of future potential in Colombia. Renew Energy 69:488-505. https://doi.org/10.1016/j. renene.2014.03.056

3. McKendry P (2002) Energy production from biomass (part 2): conversion technologies. Bioresour Technol 83(1):47-54. https://doi. org/10.1016/S0960-8524(01)00119-5

4. Demirbas A (2004) Combustion characteristics of different biomass fuels. Prog Energy Combust Sci 30(2):219-230. https://doi.org/10. 1016/j.pecs.2003.10.004

5. Baxter L (2011) Biomass-coal co-firing: an overview of technical issues. In: Grammelis P (ed) Solid biofuels for energy. Green energy and technology. Springer, London. https://doi.org/10.1007/9781-84996-393-0_3

6. Kunii D, Levenspiel O (1991) Fluidization engineering, 2nd edn. Butterworth-Heinemann, Stoneham

7. Basu P (2006) Combustion and gasification in fluidized beds, first edition. Taylor and Francis Group, Halifax

8. Geldart D (1986) Chapter 3. Characterization of fluidized powders. In: Gas fluidization technology. John Wiley \& Sons, Chichester, New York, Brisbane, Toronto, Singapore.

9. Abdullah MZ, Husain Z, Yin Pong SL (2003) Analysis of cold flow fluidization test results for various biomass fuels. Biomass Bioenergy 24(6):487-494. https://doi.org/10.1016/S09619534(02)00150-2

10. Tang J, Chen X, Lu C, Zhang Y (2012) Minimum fluidization velocity of binary particles with different Geldart classification. Adv Mater Res 482-484:655-662. https://doi.org/10.4028/www. scientific.net/AMR.482-484.655

11. Anantharaman A, Cocco RA, Chew JW (2018) Evaluation of correlations for minimum fluidization velocity $\left(\mathrm{U}_{\mathrm{mf}}\right)$ in gas-solid fluidization. Powder Technol 323:454-485

12. Ergun S (1952) Fluid flow through packed columns. Chem Eng Prog 48(2):89-94
13. Cui H, Grace JR (2007) Fluidization of biomass particles: a review of experimental multiphase flow aspects. Chem Eng Sci 62:45-55. https://doi.org/10.1016/j.ces.2006.08.006

14. Gauthier D, Zerguerras S, Flamant G (1999) Influence of the particle size distribution of powders on the velocities of minimum and complete fluidization. Chem Eng J 74:181-196. https://doi.org/10. 1016/S1385-8947(99)00075-3

15. Ye M, van der Hoef MA, Kuipers JAM (1999) The effects of particle and gas properties on the fluidization of Geldart A particles. Chem Eng Sci 60(16):4567-4580. https://doi.org/10.1016/j.ces. 2005.03.017

16. Ocanha E, Zinani F, Espinosa Mondolo R, Santos F (2020) Assessment of the effects of chemical and physical parameters in the fluidization of biomass and sand binary mixtures through statistical analysis. Energy. 190:116401. https://doi.org/10.1016/j. energy.2019.116401

17. Nienow AW, Cheesman DJ (1980) The effect of shape on the mixing and segregation of large particles in a gas-fluidised bed of small ones. In: Grace JR, Matsen JM (eds) Fluidization. Springer, Boston. https://doi.org/10.1007/978-1-4684-1045-7_37

18. Tang J, Chen X, Zhang Y, Lu C, Shen Z (2012) Minimum fluidisation velocities of burned oil sand particles. Can J Chem Eng 90:1494-1501. https://doi.org/10.1002/cjce.20650

19. Chen X, Zhong W, Heindel TJ (2017) Fluidization of cylinder particles in a fluidized bed. Adv Powder Technol 28(3):820-835. https://doi.org/10.1016/j.apt.2016.12.008

20. Rao TR, Ram JR, Bheemarasetti (2001) Minimum fluidization velocities of mixtures of biomass and sands. Energy 26(6):633-644. https://doi.org/10.1016/S0360-5442(01)00014-7

21. Aznar MP, Gracia-Gorria F, Corella J (1992) Minimum and maximum velocities for fluidization for mixtures of agricultural and forest residues with a second fluidized solid. I. Preliminary data and results with sand-sawdust mixtures. Int Chem Eng 32(1):95102

22. Aznar MP, Gracia-Gorria F, Corella J (1992) Minimum and maximum velocities for fluidization for mixtures of agricultural and forest residues with a second fluidized solid. II. Experimental results for different mixtures. Int Chem Eng 32(1):103-113

23. Paudel B, Feng Z-G (2013) Prediction of minimum fluidization velocity for binary mixtures of biomass and inert particles. Powder Technol 237:134-140. https://doi.org/10.1016/j.powtec. 2013.01.031

24. Clarke KL, Pugsley T, Hill GA (2005) Fluidization of moist sawdust in binary particle systems in a gas-solid fluidized bed. Chem Eng Sci 60:6909-6918. https://doi.org/10.1016/j.ces.2005.06.004

25. Shao Y, Ren B, Jin B, Zhong W, Hu H, Chen X, Sha C (2013) Experimental flow behaviors of irregular particles with silica sand in solid waste fluidized bed. Powder Technol 234:67-75. https:// doi.org/10.1016/j.powtec.2012.09.019

26. Karmakar M, Haldar S, Chatterjee P (2011) Studies on fluidization behavior of sand and biomass mixtures. In proceedings: 19th European Conference and Exhibition - From Research to Industry and Market, Berlin, Germany. 6-10 June 2011. Produced and published by ETA-Florence Renewable Energies.

27. Proenza-Pérez N, Travieso-Pedroso D, Blanco-Machin E, SantanaAntunes J, Verdú-Ramos RA, Silveira JL (2017) Fluid dynamic study of mixtures of sugarcane bagasse and sand particles: minimum fluidization velocity. Biomass Bioenergy 107:135-149. https://doi.org/10.1016/j.biombioe.2017.08.015

28. Fu Z, Zhu J, Barghi S, Zhao Y, Luo Z, Duan C (2019) Minimum fluidization velocity of binary mixtures of medium particles in the air dense medium fluidized bed. Chem Eng Sci 207:194-201. https://doi.org/10.1016/j.ces.2019.06.005

29. Proenza-Pérez N, Travieso-Pedroso D, Blanco-Machin E, SantanaAntunes J, Verdú-Ramos RA, Silveira JL (2018) Prediction of the minimum fluidization velocity of particles of sugarcane bagasse. 
Biomass Bioenergy 109:249-256. https://doi.org/10.1016/j. biombioe.2017.12.004

30. Yang W-C (2003) Evaluation of correlations for minimum fluidization velocity (U) in gas-solid fluidization. In: Handbook of fluidization and fluid-particle systems, First edn. CRC Press. https:// doi.org/10.1016/j.powtec.2017.10.016

31. Cardoso CR, Oliveira TJP, Santana JA, Ataide CH (2013) Physical characterization of sweet sorghum bagasse, tobacco residue, soy hull and fiber sorghum bagasse particles: density, particle size and shape distributions. Powder Technol 245:105-114. https://doi.org/ 10.1016/j.powtec.2013.04.029

32. Nikku M, Jalali P, Ritvanen J, Hyppänen T (2014) Characterization method of average gas-solid drag for regular and irregular particle groups. Powder Technol 253:284-294. https://doi.org/10.1016/j. powtec.2013.11.035

33. Coltters R, Rivas AL (2004) Minimum fluidization velocity correlations in particulate systems. Powder Technol 147(1-3):24-48. https://doi.org/10.1016/j.powtec.2004.06.013

34. Salatino P, Solimene R (2017) Mixing and segregation in fluidized bed thermochemical conversion of biomass. Powder Technol 316: 29-40. https://doi.org/10.1016/j.powtec.2016.11.058

35. Guío-Pérez DC, Rincón-Prat SL, Cáceres-Martínez LE, TibochaGuzmán DA (2016) Suitability analysis of residual biomass in Colombia for gasification in fluidized beds. In: proceedings of the 24th European biomass conference and exhibition. Amsterdam, pp 870-879. https://doi.org/10.5071/24thEUBCE2016-2CV.3.23

36. Bagheri GH, Bonadonna C, Manzella I, Vonlanthen P (2015) On the characterization of size and shape of irregular particles. Powder Technol 27(Part A):141-153. https://doi.org/10.1016/j.powtec. 2014.10.015

37. Oliveira TJP, Cardoso CR, Ataíde CH (2013) Bubbling fluidization of biomass and sand binary mixtures: minimum fluidization velocity and particle segregation. Chem Eng Process Process Intensif 72: 113-121. https://doi.org/10.1016/j.cep.2013.06.010
38. Fotovat F, Chaucki J, Bergthorson J (2013) The effect of biomass particles on the gas distribution and dilute phase characteristics of sand-biomass mixtures fluidized in the bubbling regime. Chem Eng Sci 102:129-138. https://doi.org/10.1016/j.ces.2013.07.042

39. Wen CY, Yu YH (1996) A generalized method for predicting the minimum fluidization velocity. AIChE J 12(3):610-612. https:// doi.org/10.1002/aic.690120343

40. Gupta SK, Agarwal VK, Singh SN, Seshadri V, Mills D, Singh J, Prakash C (2009) Prediction of minimum fluidization velocity for fine tailings materials. Powder Technol 196(3):263-271. https:// doi.org/10.1016/j.powtec.2009.08.003

41. Li Z, Kobayashi N, Nishimura A, Hasatani M (2005) A method to predict the minimum fluidization velocity of binary mixtures based on particle packing properties. Chem Eng Commun 192(7-9):918932. https://doi.org/10.1080/009864490510950

42. Reina J, Velo E, Puigjaner L (2000) Predicting the minimum fluidization velocity of polydisperse mixtures of scrap-wood particles. Powder Technol 111:245-251

43. Grace JR (1982) Fluidized-bed hydrodynamics, Chapter 8.1. In: Hetsroni G (ed) Handbook of multiphase systems. Hemisphere Press, Washington D.C.

44. Chyang CS, Huang WC (1988) Characteristics of large particle fluidization. J Chin Inst Chem Eng 19:81-89

45. Basu P (2011) Experimental study on fluidization of biomass, inert particles, and biomass/sand mixtures. Master thesis, University of North Texas

46. Zhong W, Jin B, Zhang Y, Wang X, Xiao R (2008) Fluidization of biomass particles in a gas-solid fluidized bed. Energy Fuel 22: 4170-4176. https://doi.org/10.1021/ef800495u

Publisher's note Springer Nature remains neutral with regard to jurisdictional claims in published maps and institutional affiliations. 